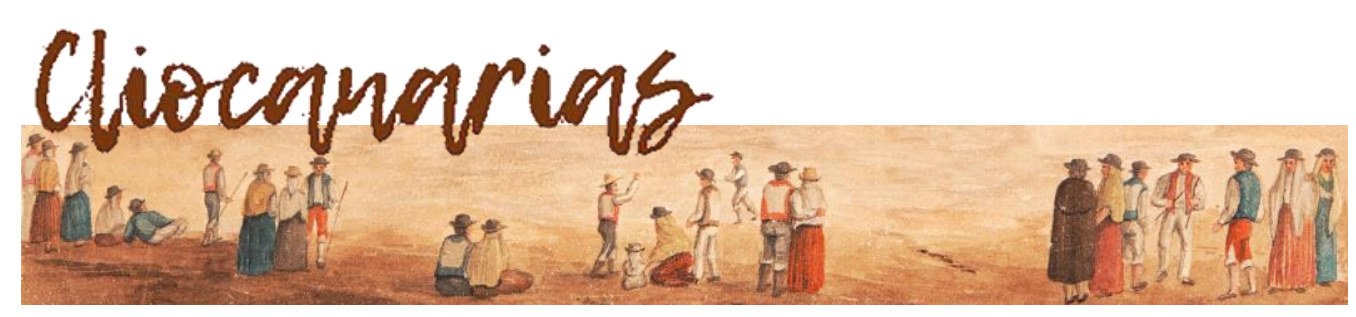

ISSN 2695-4494

https://doi.org/10.53335/cliocanarias.2021.3.07

\title{
LAS OBRAS PÚBLICAS DE QUITO EN LOS PRIMEROS AÑOS DEL SIGLO XVII SEGÚN LA DOCUMENTACIÓN DEL ARCHIVO DE INDIAS*
}

\author{
THE PUBLIC WORKS OF QUITO IN THE EARLY YEARS \\ OF THE 17TH CENTURY ACCORDING TO THE DOCUMENTATION \\ OF THE ARCHIVO DE INDIAS
}

Juan CORBALÁN DE CELIS Y DURÁN**

RESUMEN: En los años 1601-1604, en tiempos del corregidor Lope de Mendoza, se van a acometer en Quito diversas obras de urbanismo tendentes al arreglo de las calles y traida de agua potable a sus fuentes, reformas urbanísticas que ya había iniciado su antecesor Diego de Portugal. En este corto período de tiempo llevará a cabo una importante mejora de los caminos de su distrito con la construcción de siete puentes sobre sus caudalosos ríos, obras estas últimas que creemos todas ellas corrieron a cargo del arquitecto Juan del Corral.

PALABRAS ClAVE: Quito, siglo XVI, obras públicas, puentes.

ABSTRACT In the years 1601-1604, in the time of the governor Lope de Mendoza, several urban works aimed at fixing the streets and bringing drinking water to their sources, urban reforms that had already begun his predecessor Diego de Portugal. In this short period of time he will carry out an important improvement of the roads of his district with the construction of seven bridges over its plentiful rivers, works these last ones that we believe all of them were carried out by the architect Juan del Corral

KEYWORDS: Quito, 16th century, public works, bridges.

\footnotetext{
* Varias de las noticias aquí recogidas ya son conocidas, la mayoría de ellas ofrecidas sobre todo por González Suarez. En estas notas se amplian estas y se aporta la referencia del documento de donde las debió tomar, añadiendo otros nuevos datos y concretando algunas fechas. El trabajo se hace desde la distancia, sin poder consultar fuentes archivísticas y bibliográficas quiteñas que hubiesen aportado más información y completado el con-tenido (GONZÁLEZ SUÁREZ, Federico: Historia General de la República del Ecuador, tomo IV, Quito, 1893).

** Arquitecto. Académico correspondiente de la Real Academia de Cultura Valenciana. C. e.: jcorbalandecelis@gmail.com
} 
Don Luis de Velasco, virrey del Perú, a últimos de enero de 1604 había recibido una carta de don Lope de Mendoza, corregidor de la ciudad de San Francisco del Quito, en la que le decía que, como ya sabía su destinatario, el rey le había concedido ese corregimiento a Alonso García Zamor, el cual estaba ahora en el corregimiento de Hancay. Añadia que de camino a su destino se habría de detener en esa ciudad de los Reyes, de manera que cuando llegase a la ciudad de Quito vendría a ser ya entrado el invierno, y teniéndole que aguardar en esa ciudad para que le tomase residencia de su mandato, no podría salir de ella en todo el invierno por ser el camino muy fragoso y peligroso, y dado el estado de frágil salud de su esposa, doña Maria Magdalena, todo lo cual le supondría mucho gasto e incomodidad. Por tal motivo le pedía que nombrase a una persona para que en su lugar le tomase dicha residencia, con el fin de realizar el trayecto con comodidad y excusar los daños y costas. Don Lope había sido nombrado corregidor de Quito en sustitución del general don Diego de Portugal el 7 de febrero de $1601^{1}$ por un periodo de tres años, que habían concluido en ese año de $1604^{2}$.

El general Lope de Mendoza, natural de Sevilla, era hijo de don Lope de Mendoza $^{3}$, y de doña María Enríquez, deudos del duque de Medina Sidonia, y había pasado a Perú hacía 1577 avecindándose en Los Reyes, ciudad de la que sería alguacil mayor de su Audiencia, visitador general de los hospitales y capitán de la gente de a caballo. Se casó allí con doña María Magdalena de Ribera, una de las hijas de Nicolás de Ribera el Viejo, conquistador de aquella provincia, uno de los trece de la fama en la isla del Gallo. Su hermano Juan de Mendoza Mate de Luna ${ }^{4}$ casó con doña Mariana de Ribera, otra de las hijas de dicho Nicolás. Falleció en Lima, siendo alcalde ordinario de la ciudad, el 11 de noviembre de 1610, día de San Martín, sobre la una del mediodía. En la madrugada del dia siguiente fallecería asimismo su mujer doña Maria Magdalena. Sin hijos de su matrimonio, nombrarian heredero a su sobrino Luis de Mendoza, hijo de su hermano Juan.

El virrey, con fecha de 5 de marzo de ese año 1604, atendía a sus deseos y nombraba juez de residencia a Pedro Ponce Castillejo, alguacil mayor de la ciudad de Quito, para que auditase su actuación durante el tiempo que había

\footnotetext{
${ }_{1}^{1}$ AGI, Audiencia de Quito (en adelante Quito), 26, N. 19.

2 AGI, Patronato Real (en adelante Patronato), 101, R. 4. Relación para el Real Consejo de la Indias sacada por el licenciado Alonso Fernández de Castro, relator de los servicios que el general don Lope de Mendoça hizo a su magestad en Indias en tiempo de treinta años. Y de los servicios del capitán Nicolás de Ribera, padre de doña María Madalena de Ribera, suegro del dicho don Lope de Mendoza, que fue uno de los primeros conquistadores y pobladores del Pirú, y de su calidad. (Impreso). Incluye el expediente: Residencia del general don Lope de Mendoça. ${ }^{3}$ Caballero del hábito de Santiago, uno de los cuatro caballeros de la reina. Pasó a Inglaterra siendo teniente de la guardia del monarca cuando este fue a casarse. Falleció en la Corte hacia 1571 (AGI, Indiferente general, 2.090, N. 206). Según ellos, descendían de la casa de Mendoza y de Medina Sidonia, la de Arcos, de la de Alcalá y Altamira, y del almirante de Castilla don Juan Mate de Luna.

${ }^{4}$ Había pasado al Perú, la primera vez, en 1569 con el virrey Francisco de Toledo. En 1587 se encontraba en España, asistiendo a la defensa de Cádiz y del puerto de Santa María cuando fue atacado por Francis Drake. Habiendo sido nombrado gobernador de la provincia de Santa Cruz de la Sierra, pasó nuevamente a las provincias del Perú, donde hizo una importante entrada en esa provincia, fundando la ciudad de la Santísima Trinidad (AGI, Patronato, 144, R. 1).
} 
ejercido el cargo de corregidor, revisando las cuentas de su administración y tomando declaración a diferentes testigos sobre un largo cuestionario de preguntas referentes a todo ello. La noticia de esta auditoría se pregonaba en la plaza pública para que todos se enterasen de ello, colgando además el edicto en las casas del Cabildo y en la de don Lope, donde permanecería expuesto durante 30 dias. El 18 de junio se nombró escribano para que llevase relación de la auditoria a José de Madrigal, y ese mismo dia, por voz de Vicente Díaz, pregonero, se publicaba en la plaza el edicto en el que se decía: Que se hacía saber a todos los vecinos, moradores, estantes y visitantes de la ciudad y sus términos, $y$ a los caciques y principales e indios de ellos, que se iba hacer residencia del general don Lope de Mendoza, corregidor que habia sido de ella, para saber cómo había usado y administrado su cargo; asi que cualquier persona que tuviese que alegar sobre ello en su contra compareciese en el término de 30 dias a contar desde dicho día, ante dicho Pedro Ponce ${ }^{5}$, añadiendo que pasado el plazo no se admitirian alegaciones.

Dos días después, el domingo día 20, al término de la misa mayor, se publicaba el bando en el cercano pueblo de San Antonio de Pomasqui en presencia de Donato Macolla Guaçu, cacique principal y gobernador del dicho pueblo de Pomasqui, Calacalí y San Antonio, encontrándose también presente el vicario Gabriel Miño y otros muchos españoles e indios vecinos de esos lugares. Igualmente, en dias sucesivos se fue repitiendo el bando, pregonado en lengua vernácula, en Cumbayá y demás pueblos del distrito de la ciudad6.

En la revisión de cuentas y actos correspondientes al ejercicio de su cargo

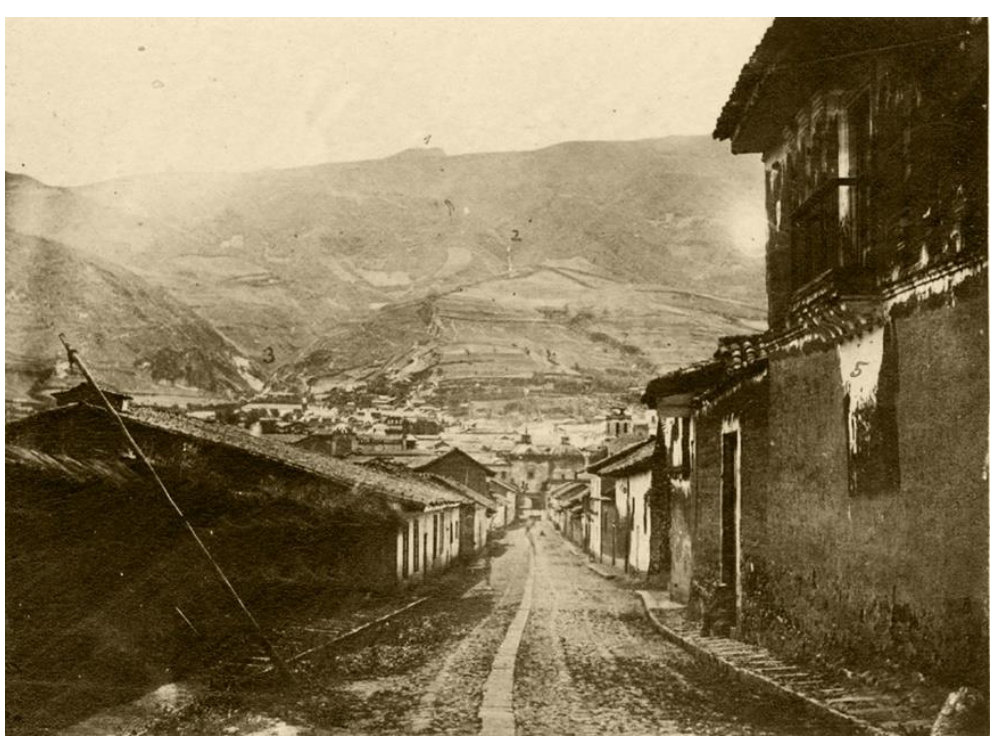

Imag. 1. Calle de la Loma. Bajando hacia Santo Domingo. (Imagen de dominio público, en adelante (idp) se va a auditar, no solo su actuación como responsable de la ciudad en materia de abastos, obras públicas y de particulares, cobro de tasas, control del juego de naipes y dados, de vagabundos y gentes de mal vivir, etc., sino que también se va a procurar averiguar si se había lucrado con su empleo, controlando si había adquirido propiedades en ese tiempo, si se había dejado cohechar, si había hecho uso de las propiedades públicas en su beneficio, etc. ${ }^{7}$.

\footnotetext{
5 AGI, Patronato, 101, R. 4. Residencia del General don Lope de Mendoça s/n. Todos los entrecomillados que no lleven su correspondiente nota al pie corresponden a este expediente. 6 Se repite el bando en Puembo, Zámbiza, Yaruqui, Nayón, Guápulo y Chillogallo, desde el que se distribuiria por los pueblos del distrito de Machachi y de Uyumbicho.

7 En la información secreta que se llevará a cabo, se le preguntará a los testigos sobre todo ello a lo largo de 63 preguntas sobre las cuales debian declarar lo que supiesen.
} 
Había llegado a Quito en diciembre de 1601, presentando la cédula de su nombramiento el día trece ante el Cabildo, el cual tras el correspondiente acto protocolario le reconocía como nuevo corregidor y lugarteniente de capitán general del virrey en esa ciudad de San Francisco de Quito y distrito de su Real Audiencia ${ }^{8}$. De estos años de su mandato, en la residencia que se le tomaba a la finalización de su empleo se incidia sobre todo en las muchas e importantes obras públicas que habia realizado durante ese breve tiempo, más que lo que han hecho otros cuatro corregidores juntos, de las cuales le estaba toda la ciudad muy agradecida.

Coincidiendo con su llegada, el Cabildo tenía entonces como uno de los temas prioritarios para la república la conducción de agua a la ciudad y la mejora de su calidad, temas tratados en sucesivas juntas en los primeros meses de 1602. En la celebrada el 4 de enero se exponía que llevaban tiempo procurando extraer agua para abastecimiento de la ciudad y se había derrumbado la acequia que la traía. Ante la falta de agua durante muchos dias se convino en efectuar diligencias para solucionarlo, acordando que dos regidores, uno de ellos Cristóbal de Troya $^{9}$, se encargasen de verificar por dónde se po-

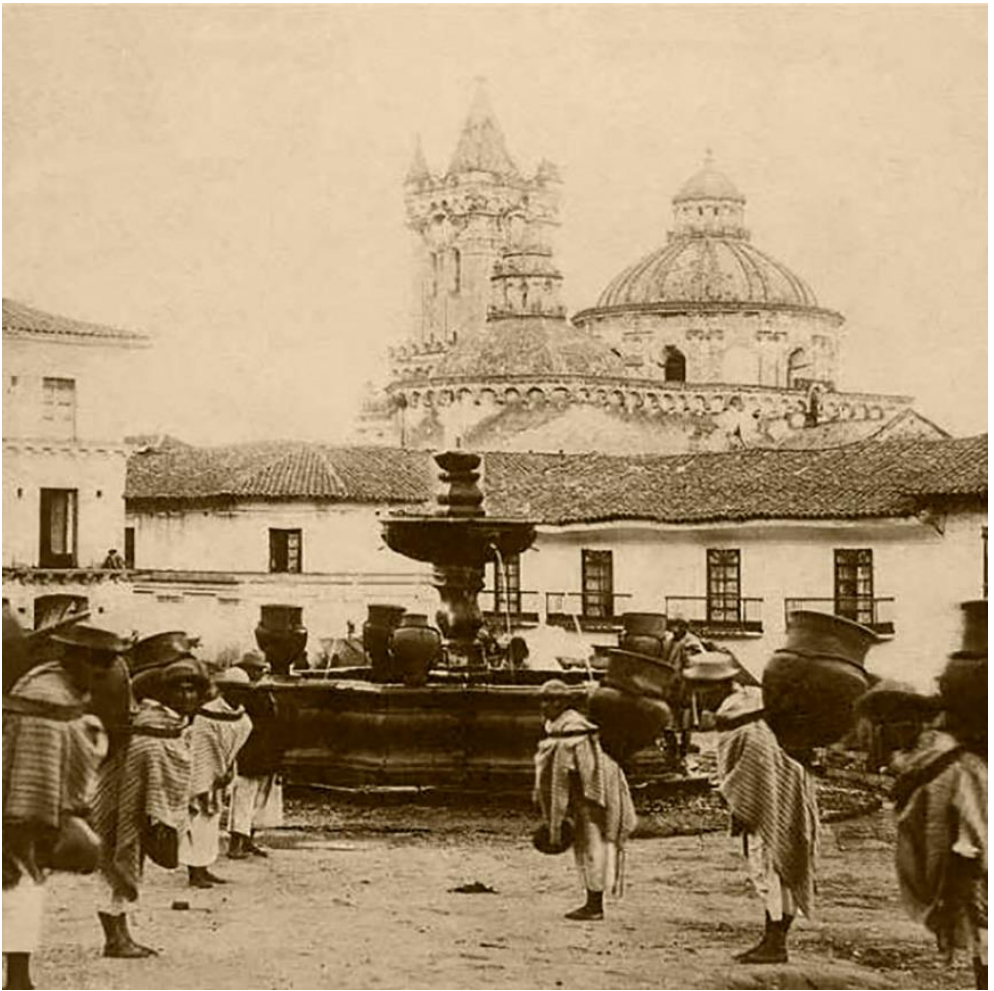

Imag. 2. Fuente de san Francisco hacia 1862 (Foto de Camillus Farrand/idp) dría sacar y traerla a la plaza. Al mes siguiente, el día ocho, el procurador general pedia que se trajese el agua llamada de Lloa, considerada idónea, pues la existente era enferma, disponiendo una visita de inspección por los regidores a esa agua de Lloa y la acequia, ya abierta, por la que debía discurrir hasta

8 GARCÉS, Jorge: Libro de Cabildos de la Ciudad de Quito, 1597-1603, tomo segundo, vol. XIV, Quito, 1940, pp. 206-218.

9 ...Dicho capitán es uno de los votos más acordados de dicho Cabildo, y que en todas las cosas de importancia su boto y parecer es el más seguido de los capitulares. Cuando se ofrece tratar de cosas del bien y aumento de la república, aderezos de puentes y caminos u otras cosas importantes al bien de ella, casi todo se encomienda a dicho capitán por ser, como es, persona de gran gobierno, inteligencia y actividad, y un hombre que con gran suavidad y agrado da fin a todas las cosas que se le encargan, por la gran plática y experiencia que tiene, y asi este testigo lo tiene por uno de los mejores republicanos de esta tierra y de los más agradables y amigo de hacer placer de toda ella (AGI, Quito, 50, N. 33). Una semblanza de este conocido personaje en CORBALÁN DE CELIS Y DURAN, Juan: "La fundación de San Miguel de Ibarra en Quito, la apertura de un camino al Mar del Sur, y el capitán Cristóbal de Troya", en Boletín de la Sociedad Castellonense de Cultura, Tomo XCIII, Castellón, 2017. 
la pila de la plaza agua de buena calidad desde los altos de Pichincha, pues la consumida entonces era insana al proceder de una ciénaga. El agua saludable surtiría la pila de la plaza mayor, mientras la existente se destinaba a la pila de San Blas. Indician en el tema en la junta celebrada el 28 de febrero de 1602 , en la que se trató la reparación de los caños y la conducción del agua llamada de la Cantera que venía a la plaza de Santo Domingo, ya que por defectos de rotura hacía mucho que no llegaba a la fuente. Así mismo, para que tuviesen agua los vecinos del barrio de San Francisco se determinó levantar una fuente cerca de la casa de Sanabria ${ }^{10}$ y mejorar la existente en la plaza

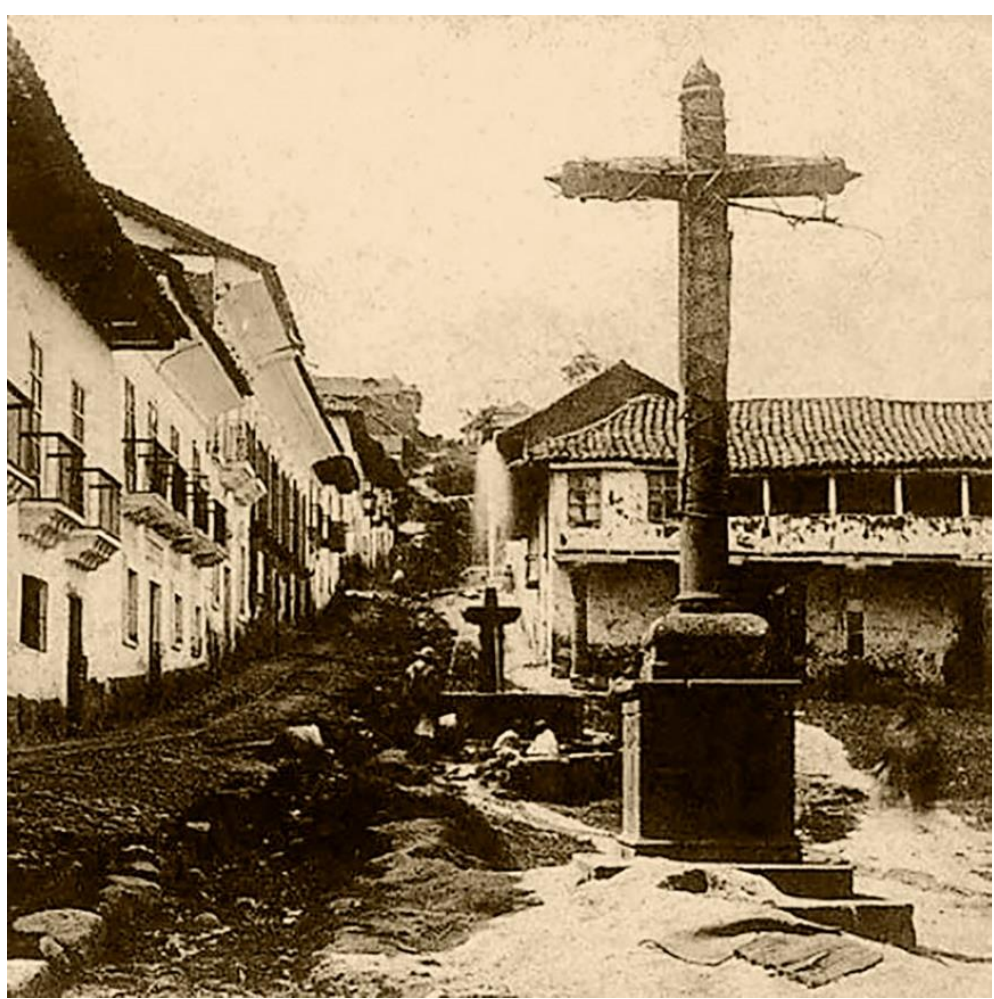

Imag. 3. Antigua calle de las Siete Cruces. Fuente de Santa Bárbara.( Foto Camillus Farrand/idp)

\section{de San Francisco ${ }^{11}$.}

Siguiendo las previsiones del Cabildo, una de las primeras labores que debió acometer don Lope, y que nos van describiendo los testigos, fue la de encauzar durante un largo trecho esa agua que llegaba a la plaza, llevando otra de mejor calidad, pues la vigente era un agua muy enferma, evitando así las enfermedades de piedra e indixecciones y crudezas de estómago que con esa otra padecian los vecinos. Según declaraba el regidor Cristóbal de Troya, habia ido junto con don Lope y otros regidores al nacimiento de un arroyo de agua que estaba a cuatro leguas de la ciudad, construyendo una acequia por caminos muy abruptos y de terreno duro, con mucho trabajo y dificultades, trayendo el agua hasta el depósito del que se proveía la ciudad, obra que había intentado su predecesor pero no había llegado a ejecutar debido a esas dificultades. Seguramente debe tratarse del agua que se trajo de Lloa, que - según vimos- ya se había comenzado a construir su acequia a primeros de febrero de 1602. Acometió asimismo las obras necesarias para que esa agua llegase a otras fuentes de la ciudad, y la faena que se solia sentir en tiempo de verano no la hay ahora, sino mucha abundancia de agua y muy buena. Se instaló una fuente en la plazuela de san Roque, se arregló la de la plaza de santo Domingo, a la que no le llegaba, así como la de

10 Debe tratarse de la casa de Francisco de Sanabria, hijo de la hermana de don Francisco Atahualpa, descendiente de los Incas (AGI, Quito, 29, N. 13). Francisco Atahualpa, hijo del Inca Atahualpa, fallecía en Quito en 1583 dejando por herederos a su hijo Alonso y a su hermana Isabel (AGI, Quito, 8, R. 19, N. 50). Isabel Atabalipa casó en primeras nupcias con Esteban Pretel y en segundas con Diego Gutiérrez de Medina (AGI, Quito, 22, N. 41).

11 GARCÉS, Jorge: Libro de cabildos..., op. cit., pp. 235, 259, 268. 
algunos conventos y casas de particulares, mandando hacer otras en distintas parroquias y barrios de la ciudad que todavía no disponían de agua, aliviando así el trabajo de los vecinos que tenían que acudir a la plaza a recogerla.

Ese mismo año 1602 se habian ampliado las ordenanzas municipales, que en lo tocante a las obras públicas trataban de regular, en primer lugar, las vías y calzadas de la ciudad añadiendo un capítulo en el que se indicaba que las calles estaban en mal estado, pues era dificultoso andar por ellas, tanto a pie como a caballo, a causa de los grandes socavones y destrozos provocados por las escorrentias y el continuo arrastre de troncos y piedras sobre la calzada. Por ello se había ordenado que se reparasen y se empedrasen aquellas calles que el Cabildo considerase conveniente ${ }^{12}$. En otro capitulo anterior se regulaba la visita que un regidor y uno de los alcaldes ordinarios debían girar a los distritos de la ciudad, al menos dos veces al año, para controlar el estado de los caminos, puentes y alcantarillas, y mantenerlos en buen estado.

En las respuestas de los testigos a las preguntas del juez de residencia sobre las obras ejecutadas por don Lope en las calles de la ciudad ${ }^{13}$, venían a decir todos ellos lo mismo reflejado en las ordenanzas: que había observado mucho cuidado en el reparo de las calles, mandando reparar aquellas que se habian desempedrado y que ya habian sido arregladas por su antecesor don Diego de Portugal, empedrando otras nuevas de las más transitadas e importantes para el comercio y trato de esta ciudad. Añadian que muchas calles, a causa de las escorrentías del agua de lluvia, estaban enlodazadas, llenas de aguaycos ${ }^{14}, \mathrm{y}$ no se podía pasar por ellas a caballo, y por otras se circulaba con mucha dificultad, pero don Lope las había dejado llanas y buenas y bien empedradas. También había rellenado alguna quebrada - a remediado algún guayco- sin poder precisar a cuál de las varias que entorpecian el desarrollo urbano se refieren ${ }^{15}$.

En la residencia que don Lope de Mendoza había hecho a su antecesor don Diego de Portugal ${ }^{16}$ igualmente se señalaban las obras públicas que este había

12 GARCÉS, Jorge: Libro de cabildos..., op. cit., p. 321.

13 Hay que tener en cuenta que los testigos contestaban a una serie de cuestiones preparadas de antemano por el juez, por lo que todos se ceñian a ellas, añadiendo tan solo algunas veces algún dato que ampliaba lo estrictamente preguntado. En este caso pensamos, por la redacción del cuestionario, que a la hora de prepararlo se tuvieron a la vista esas previsiones y ordenanzas, pues las obras que señala son iguales, e incluso a veces se señalan con idénticos términos.

${ }^{14}$ Aguayco-guayco: barranco, quebrada. En este caso, surcos en la calzada provocados por esa escorrentía.

${ }^{15}$ La de Sanguña, que discurría tras la catedral, en palabras del presidente Barros en abril de 1595, era una quebrada o foso muy grande que causa deformidad, asi al edificio como a la traza de la ciudad (AGI, Quito, 8, R. 29, N. 125). El relleno de esta quebrada, iniciado hacia 1587, se terminaba de cegar en 1610 (CORBALÁN DE CELIS, Juan: "Unas notas sobre la catedral de Quito a través de la documentación del Archivo General de Indias", en prensa).

16 Diego de Portugal, sobrino del virrey conde del Villar, había sido nombrado corregidor de Quito el 7 de junio de 1595. Presentaba su nombramiento al Cabildo el 2 de agosto de 1597. Acabado su mandato el 17 de febrero de 1601, se comisionaba al capitán don Lope de Mendoza, a quien se había nombrado nuevo corregidor de Quito, para que tomase residencia y cuentas a su antecesor don Diego de Portugal (AGI, Quito, 26, N. 45). 


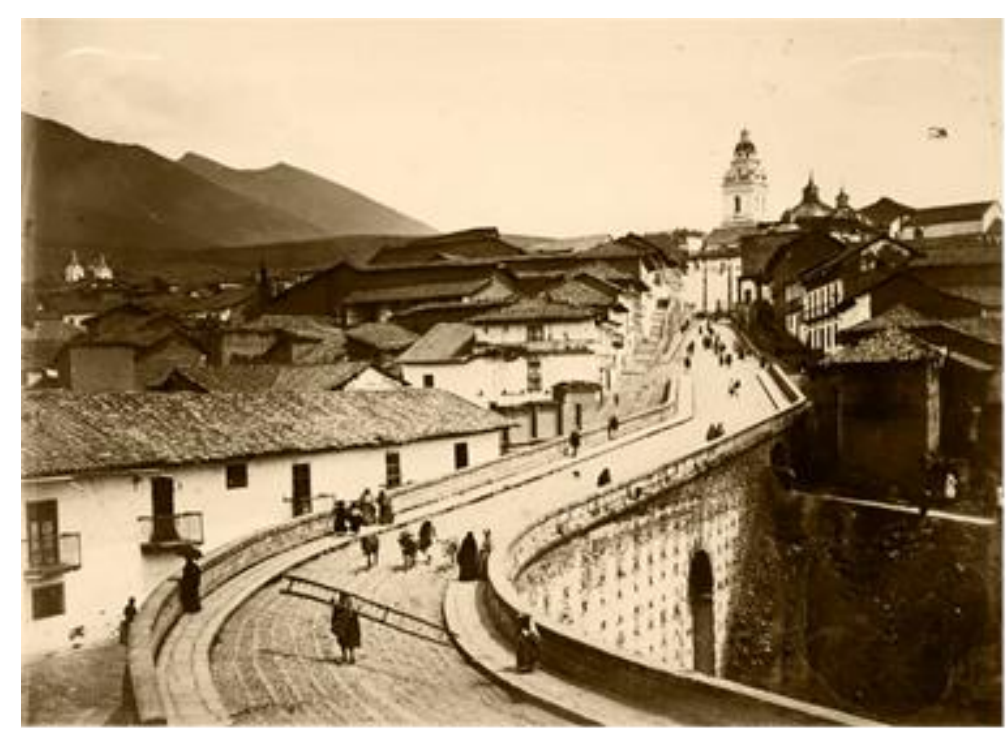

Imag. 4. Calle Maldonado. Pasando la quebrada de Santa Rosa. Hacia 1903. (idp)

realizado en la ciudad de Quito durante los pasados años de su corregimiento ${ }^{17}$. Decía don Diego - se recordará que lo repetía don Lope-, que a su llegada las calles estaban maltratadas y arruinadas, de manera que por muchas no se podía andar ni a pie ni a caballo, por lo que las mandó aderezar todas, $y$ particularmente se empedraron la calle de la entrada de la ciudad por Añaquito, desde la subida a las carnicerías hasta la esquina de las casas de Pedro Rabelo18; la que va de dicha esquina por delante de la puerta de san Agustin; la calle que va a la plaza principal desde las casas reales por el lado del monasterio de la Concepción; la que va de la plaza a las casas donde al presente vive el general don Francisco de Mendoza ${ }^{19}$, que estaba hecha pantanos, y se allanó y calzó, de suerte que se hace carrera en ella; la calle que va desde esta a las casas del capitán Ribadeneyra ${ }^{20}$; la que va desde la esquina de la casa de Luis de Cabrera ${ }^{21}$ a la plaza de santo Domingo; la que va desde la plaza de santo Domingo a san Agustin, por las casas de Alonso del Castillo ${ }^{22}$; y la que va desde la esquina de la Compañia de Jesús a la plaza de san Francisco, que por todas son ocho calles que se empedraron, allanaron y aderezaron

\footnotetext{
17 En los cabildos de esos años aparecen reseñadas las obras públicas que se quieren acometer. En el de 13 julio 1598 se acuerda aderezar las siguientes calles: la que baja a las carnicería, a espaldas de las casas reales; la de la carnicería; la de Luis Cabrera hasta la plaza de santo Domingo; la de Marcos Plaza hasta la calle a espaldas de la casa del capitán Rivadeneira; la que va a la plaza de san Agustín, hasta abajo del guayco; y la calle de las monjas de la Concepción (GARCÉS, Jorge: Libro de cabildos..., op. cit., vol. XIII, p. 147). Parte de estas calles son las que cita Diego de Portugal en su alegación.

18 Pedro Rabelo Guerrero, portugués de padres castellanos, comerciante, que llegó a Quito hacia 1554. Casó en esa ciudad en 1567 con doña Leonor, hija de Juan Vall, conquistador (AGI, Indiferente, 2.091, N. 6).

19 Francisco de Mendoza Manrique, corregidor que había sido de la ciudad de Quito en 1594 (AGI, Quito, 24, N. 13).

${ }^{20}$ Rodrigo Díaz de Rivadeneira, nombrado capitán en 1593 a raíz del motín de las alcabalas. Casado con doña Ana de Zúñiga, hija de don Francisco Ramírez de Arellano, hermano del conde de Aguilar y de doña Beatriz de Ribera y Ulloa (AGI, Quito, 25, N. 40).

${ }^{21}$ Luis de Cabrera, escribano, encomendero del pueblo de San Andrés, compró el oficio de regidor en 1599. Hijo natural de Alonso de Cabrera, nacido en la villa de Cazalla, conquistador (AGI, Quito, 35, N. 39).

${ }^{22}$ Canciller de la Audiencia y depositario general. Casado con doña Isabel Tufiño de Arce, hija de Francisco Ulloa de Toro, conquistador, que fue degollado por el tirano Gonzalo Pizarro (AGI, Quito, 87, N. 11). A Cabrera le había comprado en 1597 el Cabildo eclesiástico, por 20.000 pesos, una casa que poseía a espaldas de la iglesia, frente a la puerta del Perdón, al otro lado de la estrecha calle por la que se accedía a la plaza mayor, casa que tenía uno de sus laterales recayente a dicha plaza, sobre cuyo solar ampliaron la cabecera de la iglesia (AGI, Quito, 10, R. 7, N. 63).
} 
estando inaccesibles por los barrancos y lodos que tenian, y generalmente se aderezaron y limpiaron las demás ${ }^{23}$.

Tuvo don Diego particular diligencia y cuidado en limpiar las calles de la ciudad, procurando que siempre estuviesen limpias, y estando la calle que va por las espaldas de las casas de don Juan de Londoño ${ }^{24}$, tan llena de estiércol y basura que no se podia entrar por ella, se mandó limpiar y la aderezó, de suerte que se pudo andar por dicha calle 25 . Agregaban los testigos que estos aderezos debían estimarse más por la poca renta que la ciudad y sus propios tenian y la dificultad para que los vecinos pagasen el costo de esos arreglos. Aunque había concertado las obras para hacer la cárcel, no las pudo llevar a efecto por la falta de liquidez.

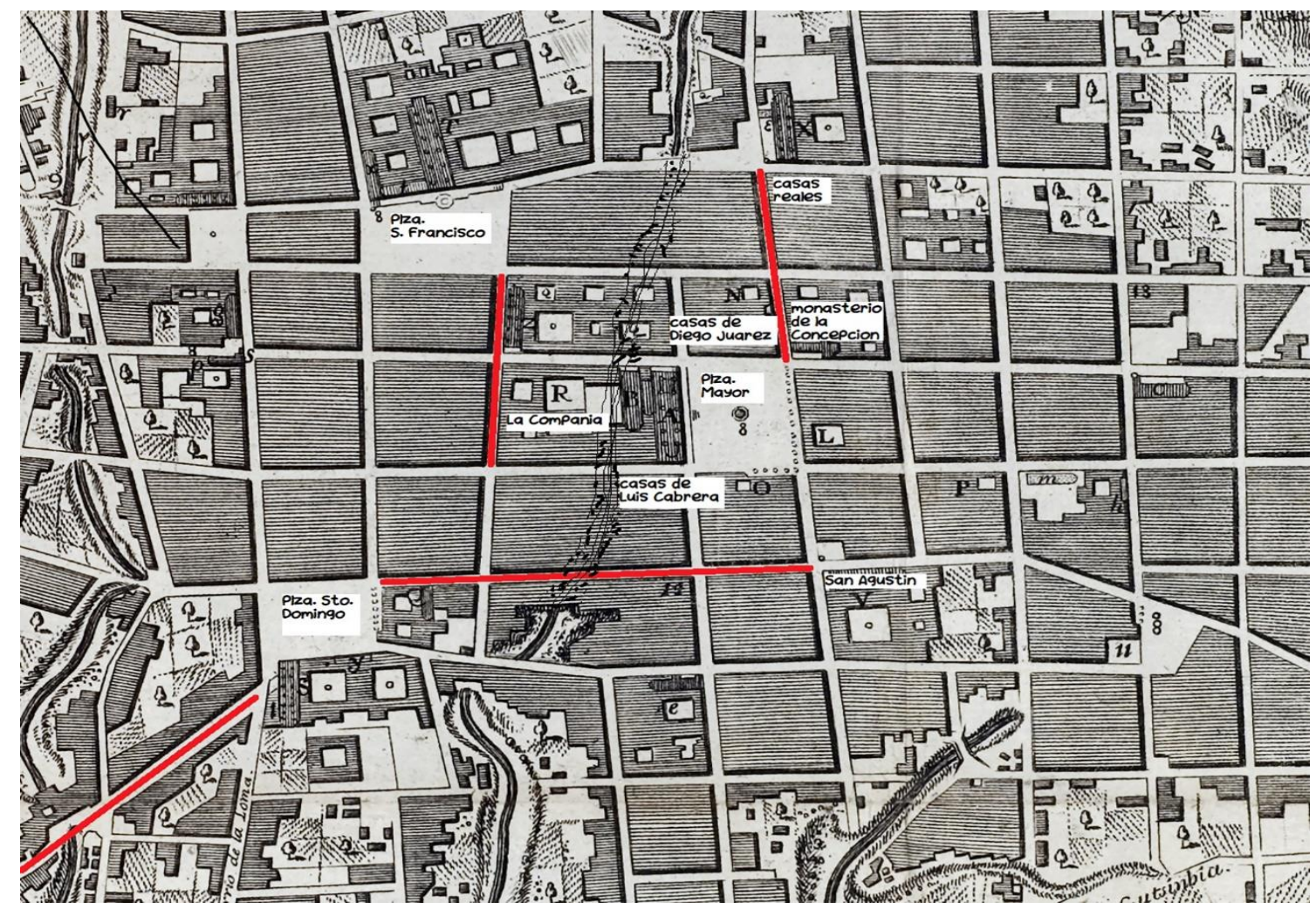

Imag. 5. Las reformas urbanísticas y el posible trazado de la quebrada de Sanguña ya cegada, sobre el plano publicado en 1748 en la obra Relación Histórica del viaje a la América Meridional ... por Jorge Juan y Antonio de Ulloa. (montaje del autor)

En descargo de don Lope se alababa también la gran ayuda que habia prestado a las obras de la catedral, cuyo templo se ha aderezado y adornado con mucha policia, y hecho un nuevo coro. Asimismo se habia ocupado de los monasterios, reedificando nuevamente dos de ellos: el de San Diego, de los padres recoletos descalzos de la orden de san Francisco, que se había trasladado de

25 AGI, Quito, 26, N. 45. Memorial de la residencia que el capitán don Lope de Mendoza, corregidor de Quito, tomó por comisión de don Luis de Velasco, virrey del Perú, a don Diego de Portugal, su antecesor, p. s/n.

24 Juan de Londoño Montenegro, nacido en 1547, hijo de Juan de Londoño, maestre de campo, y de doña Juana Calderón.

25 AGI, Quito, 26, N. 45. Ibidem, p. s/n. 
sitio, y el de Nuestra Señora de la Peña de Francia, de los frailes recoletos de la orden de santo Domingo, y todas las casas e iglesias de las demás religiones y parroquias se han aumentado en sus edificios y fábricas por haberles él favorecido en proveerles de mitayos, peones y oficiales, y limosnas que para ellas ha dado y recogido.

En la junta cabildicia celebrada el 5 de julio de ese año 1602 se proponía que se aderezase el puente de Machángara y el camino, dado que se estaba en verano y era más fácil hacerlo. Sobre este arreglo incidian los testigos destacando y alabando la reparación y mejora efectuadas en la calzada real, camino del Perú a España, en la entrada a Quito por Machángara, la cual había empedrado. Declaraban que incluso en verano este tramo se encontraba siempre encharcado y falto de parte de su empedrado debido a unos manantiales de agua sin encauzar, y a pesar del intento de reparar la calzada no se había conseguido a causa de dichos manantiales. No sabemos si esto último se afirmaba para resaltar el trabajo de don Lope, o que por entonces habian estado faltos de la dirección de algún maestro de obras, pues la solución a ese problema era bien simple y fue la que se adoptó, con el recogimiento de las aguas que hizo hacer por los lados; es decir, construyeron una cuneta a ambos lados del camino que recogía esta agua e impedia que corriese libremente por la calzada. Aducían que había ejecutado una calzada de piedra tan segura y fija que hasta ese día no constaba resquicio por el que se pudiese estropear, lo que parece indicarnos que nuevamente se ha contado con un maestro que ha construido una calzada con una buena cama rellena de ripios, cubierta de arena, y acabada con losas o adoquines de piedra: [...] habia dejado una entrada empedrada y muy llana, muy necesaria para el comercio y trato de la ciudad, y para la gente que sale y entra a ella, porque antes no se podia pasar sino con mucho trabajo, y muchas bestias perecian alli por el mal camino y tolladares ${ }^{26}$ que habia.

Imag. 6. Vadeando el río. Al fondo el puente de Machángara (I. N. P. C. Ecuador/idp)

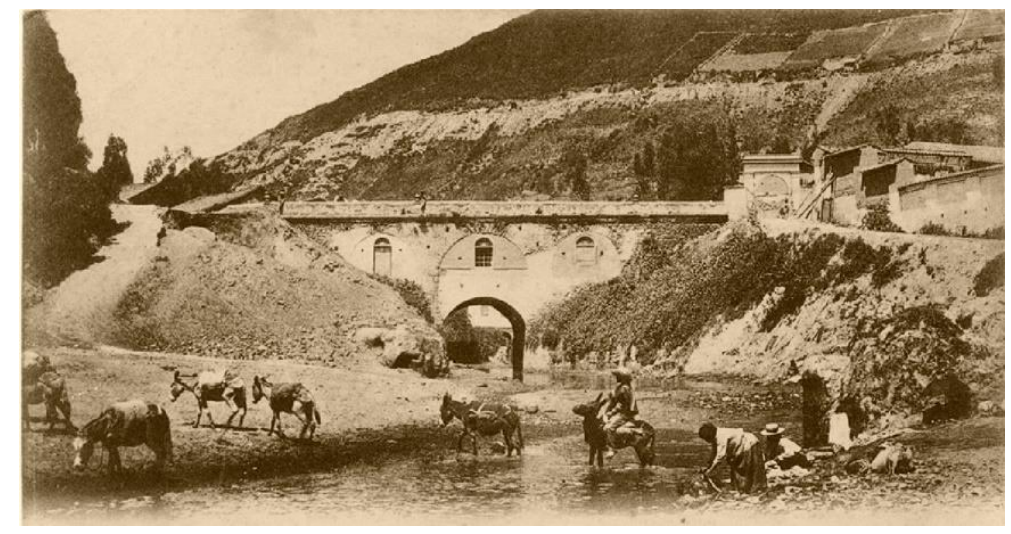

El oidor Matías Moreno de Mera nos amplia estos datos, añadiendo que habia reparado la entrada y camino de la ciudad desde los molinos de don Juan de Londoño hasta el convento de Recoletos ${ }^{27}$ y mucho más adelante. Este mucho más adelante nos lo aclara el obispo fray Luis López de Solís, matizando

26 Tollas o tremedales, terreno pantanoso, encharcado.

27 Este último convento, según vemos por la petición hecha en 1600 al Cabildo por el padre Bedón, en esta fecha debía estar ya terminado o a punto de terminarse (GARCÉS, Jorge: Libro de cabildos..., op. cit., vol. XIV, p. 57). 
que hizo una calzada empedrada desde el puente de Machángara hasta el monasterio de Recoletos, y añadía: y el camino se aderezó hasta el monasterio de Santo Domingo ${ }^{28}$.

Ese mismo día 5 de julio el procurador general decía que los originales de las ordenanzas dadas a la ciudad desde su fundación estaban estropeados y rotos, y pedia que se sacase una copia de ellas y se encuadernasen a modo de libro, con cubiertas de pergamino, y se guardasen en el archivo del Cabildo. Debe tratarse del libro al que se referia en el interrogatorio el regidor Miguel de Sandoval, el cual declaraba que don Lope habia tenido mucho cuidado con los papeles del archivo del Cabildo, y en particular con un libro en el que figura la fundación de la ciudad, que estaba viejo y maltratado por su antigüedad, del cual ha mandado hacer un traslado legitimado, con buena y legible letra, encuadernándolo para que conste y se conserve en lo venidero en dicho archivo

En una de las preguntas del interrogatorio se instaba a los testigos para aclarar si don Lope había vigilado que no se edificasen en la ciudad torres ni casas fuertes. Uno depuso que en la ciudad no habia tales edificaciones porque todas las obras eran de adobe, y don Lope había embellecido la urbe construyendo tres pares de casas de viviendas, de muy buen edificio y autoridad, con quince o dieciséis tiendas en sus bajos, que iban a suponer con su alquiler un ingreso en los propios de unos 1.500 pesos de plata anuales. Se habían levantado estos inmuebles en los corrales traseros de las casas del Cabildo

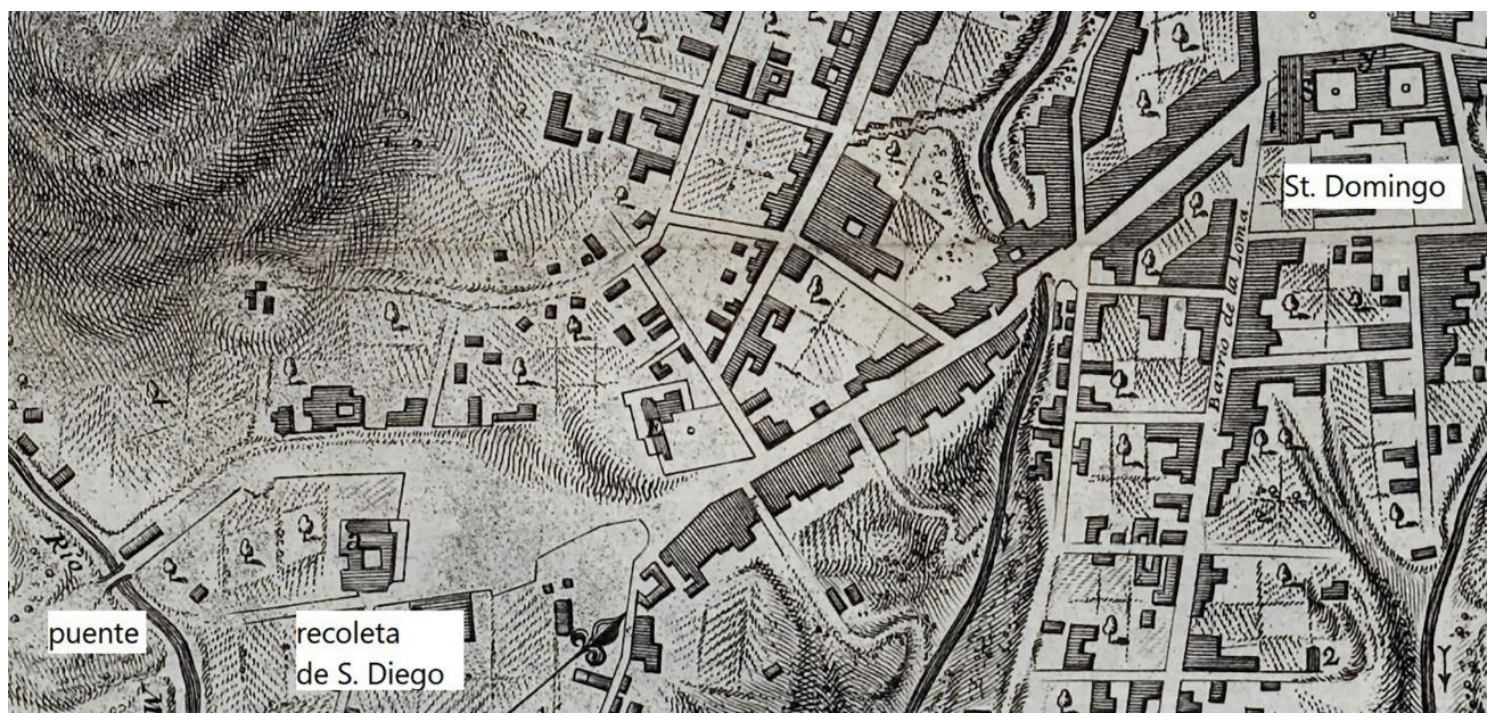

Imag. 7. Tramo de camino real desde el puente de Machángara hasta Santo Domingo en el plano de 1748 (montaje del autor)

secular, dando así servicio a dos calles aledañas, ennobleciendo aquella zona al eliminar aquellos corrales que se habian convertido en un muladar y estercolero lleno de basuras, tan perjudicial para la salud, ilustrando y engrandeciendo con ellas la ciudad. En la junta celebrada el 16 de julio de 1599 ya se había

28 Según las declaraciones, se empedró un primer tramo del camino real hasta la recoleta y se acondicionó el resto hasta Santo Domingo; es decir, un total de unos $1.100 \mathrm{~m}$, coincidentes con lo que luego sería la calle Maldonado. El paso de la quebrada de Santa Rosa, dada la importancia de esta vía de acceso a la ciudad, ya estaría resuelto con algún tipo de puente, entonces en buen uso, pues no se cita en estas mejoras urbanísticas. 
propuesto que en un solar grande que habia junto a las casas del Cabildo, que se usaban como huerta, se construyesen unas casas y tiendas para poder alquilarlas, acordándose que se eliminase la huerta y se erigiesen dichas viviendas $^{29}$. Tales obras debían financiarse con dinero de los propios y, dada la cortedad de estos, parece que se debieron retrasar hasta la llegada del nuevo corregidor.

Las casas del Cabildo se encontraban algo alejadas de las casas reales, las cuales todavia no se encontraban edificadas en la plaza mayor. Unos meses después de fundada la Real Audiencia, el presidente Santillán comunicaba al rey en carta de 15 de enero de 1564 la adquisición de dos casas muy viejas en la plaza, una de bienes del difunto obispo Arias, y otra junto a ella perteneciente a una capellanía ${ }^{30}$. Al año siguiente, viendo que era necesario gastarse mucho dinero en arreglarlas y acondicionarlas, se pensó en dejarlas y comprar otras dos que se vendían de un vecino, las cuales eran nuevas, sólidas y las vendia baratas ${ }^{31}$. Tales viviendas se hallaban algo apartadas de la plaza, a dos cuadras, casi a las afueras de la ciudad, en la parte menos poblada ${ }^{32}$, junto al convento de la Merced ${ }^{33}$. A partir de 1593 los intentos por trasladarse a ellas no cesaron hasta conseguirlo, tras la mala experiencia que tuvo la Audiencia durante la revuelta por la implantación del nuevo impuesto de las alcabalas, en que se puso cerco a las casas reales y se estuvo a punto de apresar al presidente y oidores; y parte de ello se debió, según decían, a que en caso de necesidad poca gente podia acudir en su ayuda al encontrarse tan apartada de la plaza principal. En 1611 se subastaron judicialmente las viviendas que habian sido del secretario Diego Juárez, las mejores y mejor situadas de la plaza, y ocupaban casi una manzana entera, rematándose en favor de dicho tribunal. Al año siguiente se enviaron planos al Consejo con la distribución de las distintas dependencias para Audiencia, tribunales de la Cruzada, Hacienda, etc., y se pidió permiso para comprar otras tres casas colindantes a las anteriores con las que se ocuparia toda la manzana, para mayor autoridad de las casas reales y por los inconvenientes que podrian resultar de estar pegadas con ellas ${ }^{34}$.

En las actas del Cabildo de dicho año 1602, en las nuevas ordenanzas que comentábamos se señalaba que, dado que los caminos y puentes de la ciudad y su distrito necesitaban ser reparados, además de la falta que había de estos últimos se encargaba un informe sobre qué caminos había que reparar y qué puentes era necesario erigir ${ }^{35}$. Según copia que sacaba el escribano del Cabildo años más tarde, el procurador general de la ciudad y algunos caciques habian pedido que se edificasen los puentes de Guayllabamba, Tumbaco y Alangasí, en el valle de Chillo, y habiéndose hecho ciertas averiguaciones sobre ello el presidente y oidores de la Audiencia dispusieron que se llevasen a

29 GARCÉS, Jorge: Libro de cabildos..., op. cit., vol. XIII, p. 328.

30 AGI, Quito, 8, R. 1, N. 1.

31 AGI, Quito, 8, R. 2, N. 2.

32 AGI, Quito, 9, R. 14, N. 107.

33 GONZÁlEZ SUÁREZ, Federico: Historia General de la República..., op. cit., p. 86.

34 AGI, Quito, 9, R. 15, N. 115.

35 GARCÉS, Jorge: Libro de cabildos..., op. cit., vol. XIV, p. 328. 
cabo estas obras y se repartiese entre todos los interesados el dinero pertinente para materiales, maestros y oficiales. Fueron nombrados diputados para hacer dicha repartición, y lo demás necesario para la obra, los regidores Juan Sánchez de Jerez Bohórquez, Luis de Cabrera y Cristóbal de Troya, a los que se confirieron poderes para su cobranza.

Por entonces los ríos se cruzaban, si era posible, por aquellos puntos que eran vadeables que, en terrenos abruptos y de ríos encañonados, eran difíciles de encontrar, teniendo a veces que recorrer grandes distancias para dar con ellos. Si esto no era posible había que recurrir para su paso a las tarabitas o garruchas, a puentes colgantes de maromas tejidas a base de fibras vegetales, o más elaborados de madera para los caminos de mucho tránsito. Esta manera de salvar los ríos era sumamente peligrosa, sobre todo en épocas de lluvia, con los ríos crecidos. Constantemente se alude en la documentación que hemos manejado a la numerosa mortandad que provocaban, y no solo por su paso, sino también durante el continuo trabajo de mantenimiento y reposición de los mismos, tarea de la que se encargaban los indios.

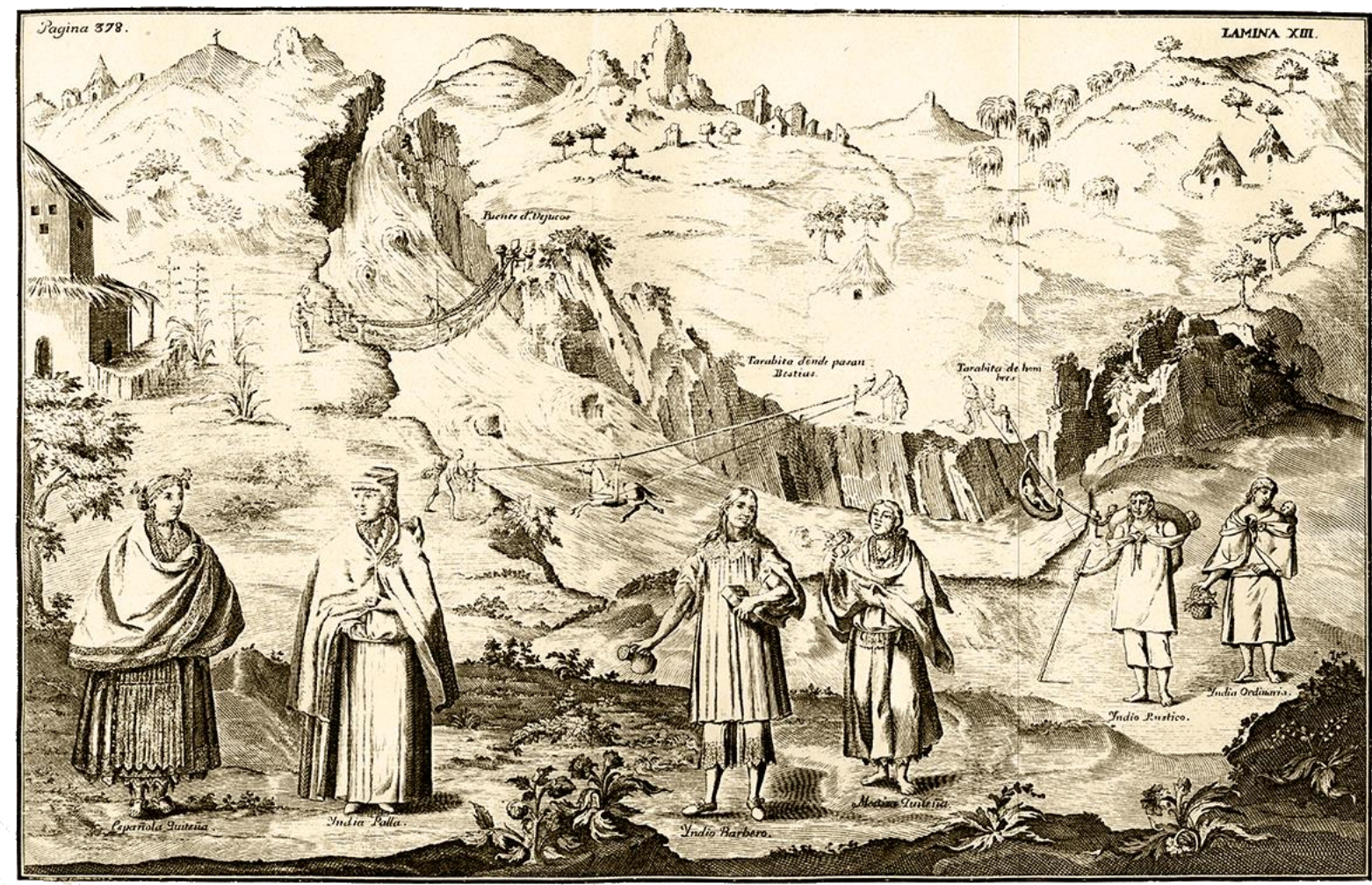

Imag. 8. Ejemplos de la gente de Quito... (sobre la quebrada: tarabitas y puente de bejucos) Grabado de la obra citada Relación Histórica del Viaje..., Madrid, 1748. (idp)

Según testificaba Miguel de Sandoval ${ }^{36}$, en la ciudad de Quito y su término, antes de la llegada de don Lope, no había ningún puente de consideración, sino que todos eran de madera. La labor más importante que llevó a cabo Lope de Mendoza durante su corta estancia en Quito como corregidor fue precisamente subsanar esta falta tan necesaria de puentes, desempeño por el que,

36 Miguel Fernández de Sandoval, capitán, regidor y vecino de Quito, casado con doña Ana de Sandoval, viuda, hija del capitán Diego de Sandoval, conquistador, matrimonio del que no tuvieron hijos. Viuda de Juan de la Rea, había heredado de este la encomienda de Chimbo (AGI, Quito, 46, R. 55). 
según Cristóbal de Troya, se había granjeado la fama de gran republicano y verdadero padre de toda esta tierra, donde quedará perpetuado su nombre por las obras heroicas que ha dejado. Estas, o su vestigio, quedaron hasta nuestros días, pero su recuerdo se debió perder pronto. Había edificado puentes en los rios con más riesgo que habia en este distrito y donde se habian ahogado muchos indios por ser los caminos muy ordinarios y pasajeros, remediando con ello no solo estas irracionales muertes que eran muy grandes, sino también el cansancio y trabajo ordinario de los naturales en acarrear la madera de dichas puentes, que unas se los llevaba el rio y otras de podridas se caían, además de estar en partes tan incómodas como lo estaban.

Anterior a la llegada de don Lope tenemos referencia de que en marzo de 1576 el Cabildo pagaba a Antonio Lorenzo 50 pesos que le restaban por los dos puentes que se obligó a levantar, uno junto a la calle de Carlos de Salazar

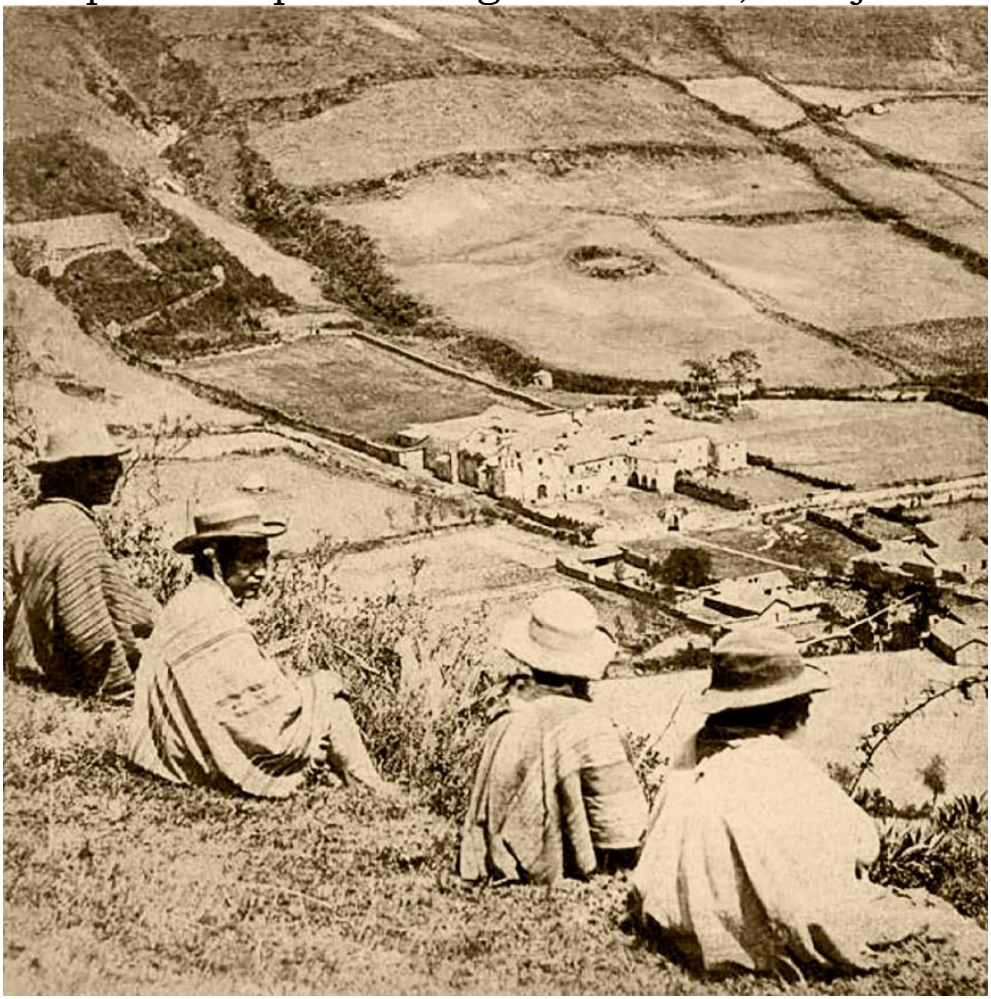

Imag. 9. La Recoleta hacia 1862, entonces a las afueras de Quito (Foto Camilo Farrand/idp) y el otro en la calle en que vivía el capitán Antonio Morán ${ }^{37}$. Se trataba de puentes urbanos para el paso de algunas de las quebradas de la ciudad, que no sabemos si serían de cal y canto. Unos años después Francisco Becerra, maestro de architectura, estuvo trabajando en Quito en los años 1580-1583, dando trazas y orden con que se hiciesen las iglesias del monasterio de Santo Domingo y San Agustin, y asimismo dio trazas para hacer tres puentes en los ríos comarcanos de dicha ciudad, que fue orden muy principal $y$ muy necesaria y en lugares muy fragosos, puentes que suponemos serian de calicanto a pesar de lo aseverado por el regidor Sandoval en su declaración. Mientras afrontaba estas obras, recibió carta del virrey don Martín Enríquez para acudir a la Ciudad de los Reyes a hacerse cargo de la traza y obra de la cate$\mathrm{dral}^{38}$.

${ }^{37}$ GARCÉS, Jorge: Libro de Cabildos de la Ciudad de Quito. 1575-1576, vol. VIII, Quito, 1935, p. 204.

38 AGI, Patronato, 191, R. 2. Estas noticias y otras referentes a Becerra tomadas de este expediente las daba a conocer en su día Ceán Bermúdez (CEÁN BERMÚDEZ, Juan Agustín: Noticias de los Arquitectos y Arquitectura de España desde su Restauración, Madrid, 1829, pp. 56-58). El documento es una petición que presenta en 1584 al rey para que le confirme el título de maestro mayor de los reinos del Perú. Da cuenta de su genealogía y describe los trabajos que ha hecho en Castilla, en la Nueva España y en el Perú. Presentaba también los 
En cumplimiento de las nuevas ordenanzas, el Cabildo diputaba ese año 1602 a las personas que debian ir a reconocer los puentes de la ciudad y su término e informar sobre ellos, comisión formada por dos regidores y algunos maestros de obras, a los que acompañó también don Lope, en que puso gran calor yendo dos y tres veces con oficiales y personas expertas al lugar donde se habia de hacer dicho puente. En este caso se están refiriendo al puente de Guayllabamba, y uno de los expertos sería, como adelantamos, el maestro cantero Juan del Corral. Don Lope llevó a cabo la construcción de cinco puentes de mampostería, en poco tiempo y a bajo coste, que habia espantado a la gente por ser edificios muy grandiosos y costosos, en Guayllabamba ${ }^{39}$, Tumbaco, Guápulo, Alangasí, y Pinta (Pintag), puente este último que debe ser el mismo que unos testigos llaman Chillo y otros Sangolquí, además de dos nuevos puentes de madera en las quebradas del río Chiche y Pedro Díaz, reparando y mejorando algunos de los existentes. En el del río Chiche, donde no habia puente ni parecía que se pudiese hacer, se alzó un pilar central de cal y canto, que para uno de los testigos es el más importante de esta tierra, porque se han ahogado en ese rio por no haber puente muchos indios, siendo al menos los cinco primeros, en palabras de Diego Rodríguez de Ocampo, de obra fuerte, perpetua y muy necesaria para aquellos rios, por ser valles que trajinan a esta ciudad con trigo, harina $y$ otras legumbres, $y$ tratos, $y$ estos puentes son de mucha consideración y necesarios para el pasaje, trato y comercio de aquellos valles ${ }^{40}$.

Francisco del Castillo, vicario del pueblo de Tumbaco, por el que discurría el camino real, declaraba que don Lope había estado en dicho pueblo con su mujer, hijos y criados, durante tres o cuatro meses, asistiendo a las obras, poniendo grandisimo calor y cuidado en que se acabasen (como se acabaron), y con su presencia $y$ regalándoles de su propia hacienda mesa y comidas, los indios trabajaron en el puente de Tumbaco con gran amor y voluntad. Además de referirse a los puentes ante-

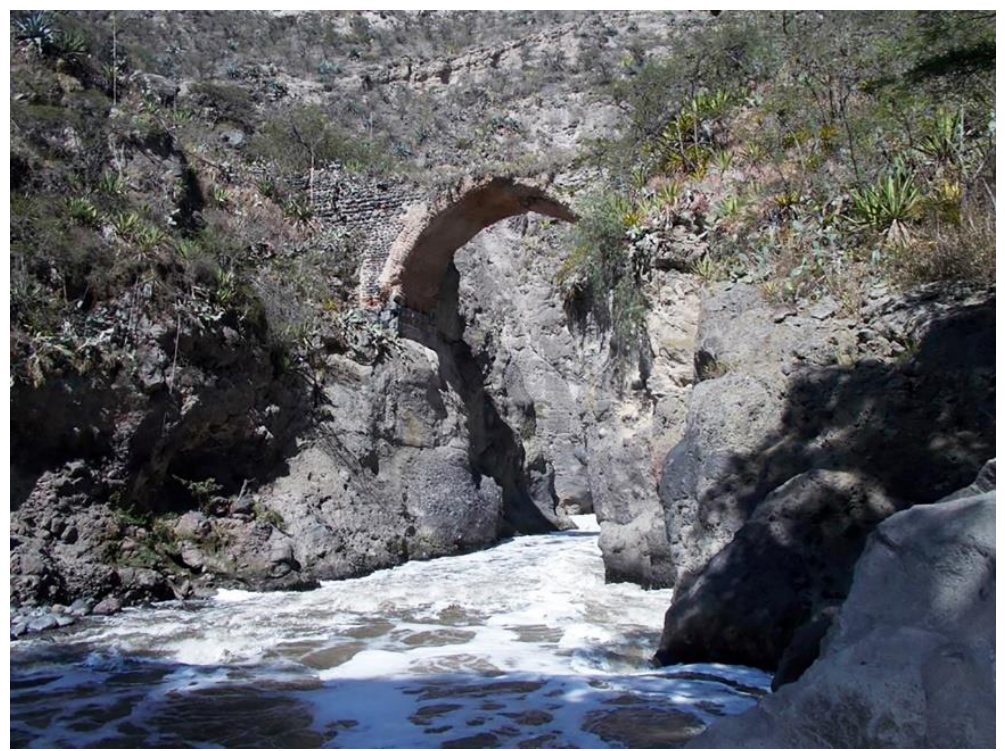

Imag. 10. Un viejo puente sobre el río Guayllabamba (idp) riores de Guápulo y Guayllabamba, afirmaba que había mandado hacer otros

títulos de maestro mayor de las iglesias catedrales de las ciudades de México, Puebla de los Ángeles, Lima y Cuzco.

39 En el cabildo de 15 octubre 1599 se había tratado la conveniencia de levantar el puente sobre el río Guayllabamba, comisionando para ello a Martín Pérez de Recalde (GARCÉS, Jorge: Libro de cabildos (1597-1603), vol. XIII, p. 362.

40 AGI, Quito, Patronato, 101, R. 4. 22 de junio de1604. Testimonio de Diego Rodríguez de Ocampo. 
dos con estribos de cal y canto en el río de Puembo (seguramente uno de ellos, el del puente del río Chiche), en enclaves tan necesarios como los anteriores, donde nunca los había habido a pesar de su necesidad. Además del beneficio para los indios con esta obra, evitando el peligro que ordinariamente corrian de ahogarse en el río, había resultado otro no menor como el descubrimiento junto a sus pueblos de algunas canteras de cal, así como la construcción de unos hornos donde se habian cocido esta y los ladrillos necesarios para dicha obra, que ahora aprovecharian ellos.

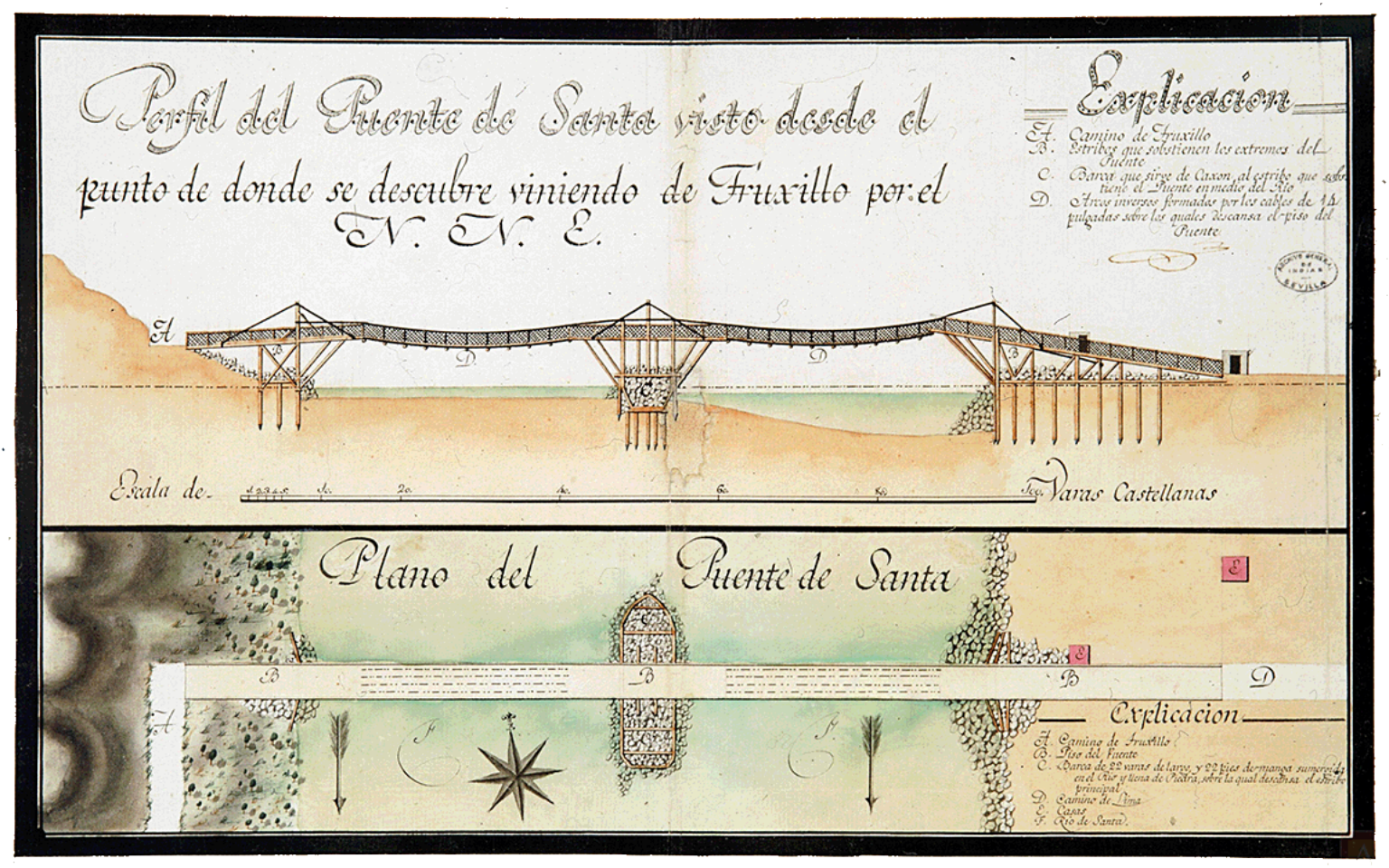

Imagen 11. Puente colgante sobre el río Santa, con apoyo central. Año 1811 (AGI. MP-Perú-Chile, 167)

Otro de los testigos, Antonio del Pino Argote ${ }^{41}$, incidia en el bien que había supuesto para los indios los puentes dispuestos por su gran necesidad, no solo por evitar que se ahogasen, sino por relevarlos del continuo trabajo, cansancio, vejación y cuidado que se tenía en renovar los anteriores, trayendo la madera de partes muy lejanas, y otros muchos trabajos que pasaban, siendo como era forzoso, continuo e inexcusable practicar semejantes reparos. Alababa los cinco puentes construidos de calicanto, y añadía que los dos de madera establecidos en las quebradas de Chichi se habian ejecutado con fuertes estribos de cal y canto. Todos ellos habían sido muy importantes, pues cuando venian las quebradas crecidas se tenia que detener la gente de una y otra parte, y si se echaban al río se ahogaban, como había acontecido con muchos indios y españoles en esas quebradas. Respecto a los nuevos puentes de la

$41 \mathrm{El}$ tesorero Antonio del Pino Argote, vecino de Quito, donde casó con doña Luisa de Cózar Valenzuela, era natural de Baeza, hijo del capitán Martín de Vilches. Había llegado a las Indias en 1586 como alférez de las galeras que trajo su tío el general Diego de Noguera Valenzuela. Fue corregidor de Popayán y Jaén de Bracamoros, e interino de Loja y Cuenca. Una semblanza de este personaje en CORBALÁN DE CELIS Y DURÁN, Juan: "Un siglo de Quito a través de los prebendados de su iglesia. El deán Antonio del Pino Argote" [<Independent.academia.edu/JuanCorbalándeCelis>]. 
quebrada de Chiche, otro de los testigos deponía que uno de ellos se habia hecho con calzada de cal y canto y el otro de piedra, que suponemos se está refiriendo a los estribos y no al tablero de aquellos. El doctor Matías Moreno de Mera, oidor de la Audiencia, repetía en su declaración los cinco puentes que don Lope había resuelto fabricar en el término de Quito a cuatro leguas de ella, en el rio de Guayllabamba, un puente suntuoso de piedra de gran edificio y mucha perpetuidad; otro en el rio de Tumbaco de cal y canto, muy grande; y otro junto al pueblo de Guápulo sobre un río que por alli pasa, en el camino de Tumbaco a Cumbayá; y otros dos de cal y canto y ladrillo en los ríos de Alangasí y Chillo, rios muy peligrosos.

De todos ellos, la obra más importante fue el puente en el caudaloso, y de fuerte corriente, río de Guayllabamba, que en boca de los testigos fue de los primeros de calicanto y ladrillo edificados Perú ${ }^{42}$, en un mal paso para ir al Perú y venir a esta ciudad por el camino, que es el real, de todo el reino y gobernación, y el de Popayán y del Perú por la vía de tierra, en un sitio que pareció imposible $y$ donde no se habian atrevido hasta ahora aunque muchas veces se habia intentado, con lo que se ahorra media legua de mal camino, y aseguró el paso con una puente que hizo en dicho vado, tan suntuosa y grande, que a dicho de todos los hombres que han estado en España es obra que puede competir con las mejores de ella. Resultó ser una puente suntuosa de piedra, de muy grande y suntuoso edificio, con que excusó muchas muertes de indios $y$ españoles. Según relataba Bartolomé Nobalino, por el puente de Guayllabamba era abastecida y provista no solo la gobernación de Popayán, sino también esta ciudad de ganado y otras cosas necesarias, y fuera de esta gran comodidad tiene otra, que lo es mucho, porque se excusó haciéndose donde se hizo, una gran legua de mal camino y resistidero de sol, tan enfangado y peligroso que muchos de los naturales enfermaban pasando por el camino, donde antes estaba una puente de madera, para la comodidad de tantos con riesgo de su salud, que estuvo muy grande por la ordinaria asistencia que hacia con su mujer y casa a la obra de dicha puente, además del gasto grande que en ello tuvo regalando por muchos dias y dando de comer a los oficiales de la obra, que

\footnotetext{
42 En febrero de 1551 se pedian informes a la Audiencia de Lima para que indicase en qué lugar se debía construir el puente que pedía el capitán Jerónimo de Aliaga en nombre de la ciudad (AGI, Lima, 566, L. 6, fols. 348v-349v). Unos años después, en 1556, en tiempos del marqués de Cañete, se estaba fabricando en Lima un puente de piedra, primero de este tipo sobre el río Rímac. Correspondiente al período entre el 1 de julio de 1556 y el 17 de septiembre de 1557 , en una relación de los pagos que el virrey ha mandado librar por la caja real vemos que se pagaban 5.000 pesos a Baltasar de Armenta para el edificio de la puente de esta ciudad, los cuales se pagarian de la sisa dispuesta para dicha obra. Se pagaban también las siguientes cantidades para el puente que se estaba levantando en el río Jauja: a Martin de Garin, vizcaíno, cantero, se le abonaban 150 pesos; a Pedro de Aguirre, maestro de cantería, para que comprase diversas herramientas, 300 pesos; a Gonzalo Hernández, mercader, 105 pesos por ciertas herramientas entregadas a Juan de Robles, y otros 69 pesos para una sierra grande y otras cosas que se habían enviado al valle de Jauja para el puente que alli se edificaba. La caja real, por orden del virrey Andrés Hurtado de Mendoza y Cabrera, habia satisfecho también 10.000 pesos a un oficial para que compusiese cal y ladrillos, so color que es beneficio de la república para que abarate y se hagan buenos edificios en este pueblo (AGI, Indiferente, 738, N. 14). Al parecer, el marqués de Cañete había sido el introductor de este tipo de puentes de cal y canto [BÜHLER, Dirk: "La construcción de puentes en las ciudades latinoamericanas como empresa de ingenieria civil...", en KINGMAN GARCÉS, Eduardo (comp.): Historia social urbana. Espacios y flujos, FLACSO, Ecuador, Quito, 2009].
} 
con su asistencia se animaron a acabar en breve tiempo una obra en la que habia trabajo que hacer muchos años, porque se hizo en un vaso muy ancho, con dos arcos, el uno en medio del rio, en que se trabajó para desviarlo por otra parte; por lo cual y esta dificultad que tenia no se habian atrevido hacer el puente en dicho paso, que es una de la más grande y heroica obra que se ha hecho en estas partes, en que puso don Lope gran calor yendo dos y tres veces con oficiales $y$ personas expertas al lugar donde se habia de hacer dicha puente, que tuvo gran dificultad. Y lo que no es de menos consideración, asi en esta obra como en las demás, es el poco coste con que se han hecho y la brevedad que se han acabado, acudiéndose a un tiempo a una y otra, que parece imposible poder acudir un hombre solo a la menor de ellas y con tanto coste de su hacienda, haciendo el gasto de todas las visitas que se hacian a los lugares donde se habian de plantar dichas puentes, llevando consigo oficiales y personas del Cabildo y otras muchas que se agregaban a esto.

Para la edificación de los puentes de Guayllabamba y Tumbaco se había desplazado a esos pueblos con toda su casa durante un tiempo, gastando mucho en dar de comer y regalar a los maestros y oficiales que en ellos trabajaban y a los muchos que los iban a ver. Resulta llamativo el comentario de Cristóbal de Troya al referirse a estos puentes, de los cuales afirmaba que los había visto todos, seguramente porque fue uno de los regidores comisionados por el Cabildo para su inspección, y añadia: Estas puentes eran las más bien acabadas que habia en todo el Perú, y dos de ellas, que eran las de Guayllabamba y Tumbaco, habia oido decir a muchas personas fidedignas que habian estado en Italia $y$ otras partes que eran tan buenas como las mejores de todos ellos, así por su traza y buena obra, por estar la puente de Guayllabamba en un rio muy grande y caudaloso, en medio del cual se sacó un arco de dos sobre que está fundado con mucha grandiosidad.

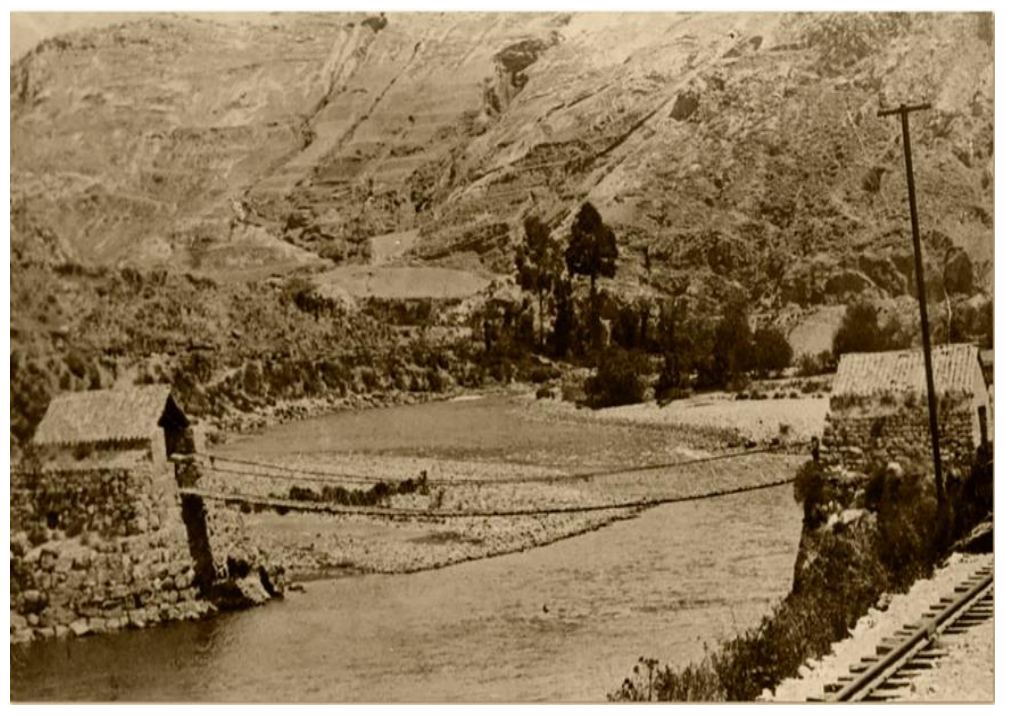

Imag. 12. Puente colgante sobre el río Mantaro (idp)

En la declaración secreta tomada a los caciques, don Felipe Guara, gobernador de Pisto, al parecer hombre precavido - como parece deducirse de su declaración-, reconocía que don Lope lo había tratado correctamente, sin agravio ni vejaciones, y que mirándolo bien se quejaba de que le había tenido preso algunas veces para las obras de los puentes que habia ordenado erigir, 
los cuales habian sido para bien de todos los indios, los cuales se quejaban de que los prendía y compelía a que trabajasen y trajesen cal y ladrillo para las obras; pero que después ha comprobado que todo era para bien suyo, y lo había resuelto con tanta mansedumbre que lo hacía como padre de dichos naturales, y aunque había cogido algunos indios de su gobernación cuando fue preciso lo hizo con razón y sin agraviarle por conocer, como conoce este testigo, que para los naturales indios es menester brio en las justicias porque los estimen y respeten, mayormente a dicho don Lope.

Entre las demandas presentadas en el plazo señalado estaba la del licenciado Blas Torre Altamirano, provisor fiscal para la defensa de los caciques y principales del pueblo de Cotocollao, el cual presentaba relación de los indios que habian trabajado en la obra del puente de Guayllabamba y el salario que se les adeudaba, relación que - dada la escasez de noticias relativas a los costes- nos parece interesante reseñar. Se ocuparon 130 indios en traer a la obra ciento treinta fanegas de cal de la calera de Pançallo, que estaba a ocho leguas $^{43}$ (unos 44,5 km), y ciento sesenta y cuatro arrobas (unos $1.900 \mathrm{~kg}$ ) de carbón, para cocerla. Otros 50 indios estuvieron trabajando cada uno de ellos trece días, hasta que se acabó la obra, que duró ocho meses. Trajeron los indios de las montañas de los Yumbos diversas maderas ya procesadas: diez vigas, cuarenta cuartones, dieciséis cumbreras y cuatro palos morochos grandes, que les costó gran trabajo sacarlos de las montañas y llevarlos al río, de todo lo cual no se había pagado nada hasta entonces a los indios.

Además de esto, los indios reclamaban 98 pesos y 7 tomines de plata que gastaron en alquilar caballos y carretas para llevar dicha carga de cal desde el pueblo de Pancallo al puente (esta vez decían que estaba a doce leguas de camino, que se caminaban en dos días de dos jornadas), y en haber comprado las 53 cargas de carbón, cortado y hecho en la montaña de Calacalí por ellos mismos y con sus herramientas, así como la madera, todo lo cual entregaron a Juan del Corral, maestro y artífice de la obra de dicha puente. Y todo este gasto no lo hicieron por su voluntad, sino para evitar las molestias y malos tratos de dicho maestro, los alguaciles y otras personas, que les decian que todo era por orden del corregidor.

Querían que se les pagase la madera y el carbón, pues de ellos se había aprovechado dicho Juan del Corral, al que acusan de haber ocupado a los carpinteros que tenía en dicho puente en labrar esa madera y la demás que habian traído otros indios, haciendo cajas, escaños, bufetes y otras piezas de carpintería para sus granjerias, y gastando el carbón en estribos, frenos y otras cosas, empleando para ello a los indios herreros en la obra, sin atender al sudor y trabajo desplegados con lo anterior, además del trabajo personal durante nueve meses en la obra de dicho puente, de todo lo cual no se les había pagado cosa alguna ${ }^{44}$.

\footnotetext{
43 En el Perú una legua equivalía a 5,56 kilómetros (GARZA MARTÍNEZ, Valentina: "Medidas y caminos en la época colonial: Expediciones, visitas y viajes al norte de la Nueva España (Siglos XVI-XVIII)", Fronteras de la Historia, vol. 17-2, 2012, p. 192). Una arroba equivalía a 11,5 kilos.

${ }^{44}$ El herrero Andrés Tituaña reclamaba lo que se le debía por el trabajo desempeñado durante cinco semanas con su fragua y herramientas llevadas al puente, donde confeccionó 1.200
} 
De la obra civil atribuida a Corral en Quito se conocía por González Suarez el puente terminado en 1607 sobre el rio Pisque, noticia que debió leer en su día en la carta que el presidente Miguel de Ibarra enviaba al rey en junio de 1606 dándole noticias de la fundación de la villa de Ibarra por el capitán Cristóbal de Troya, y que en el camino real, a siete leguas de la ciudad, había mandado construir un puente para atravesar el río Pisque, para el que se había dispuesto una derrama de 3.000 pesos entre los pueblos interesados, encargando la obra a Joan del Corral, maestro cantero. Además, facilitaba noticia de otras dos obras suyas al añadir que ya había construido otros puentes en Guayllabamba ${ }^{45}$ y en el valle de Chillo, en ríos caudalosos como aquel ${ }^{46}$. En mayo de 1607 Ibarra comunicaba al rey que la erección del puente del río Pisque, de la que ya le había dado aviso, así como de lo importante que era para esa provincia, se hallaba muy adelantada y la acabaría en tres o cuatro meses. Añadía también que en anteriores cartas había noticiado sobre los tres puentes practicados en el valle de Chillo, a dos leguas de la ciudad, además de los otros dos ordenados por el virrey en Guayllabamba y Tumbaco ${ }^{47}$.

La noticia de la autoría del puente de Guayllabamba aparecía -como indicábamos - en las actas del Cabildo y se repetía junto a la noticia de otros puentes en documentos coetáneos, como constatamos en las cartas al Consejo del presidente Ibarra, dada la repercusión que tuvieron esas obras ${ }^{48}$. Estas noticias las recogía posteriormente González Suarez. Ya más recientemente Piedad y Alfredo Costales señalaban, sin citar referencias, que Corral había construido más de media docena de puentes ${ }^{49}$. Carmen Fernández aportaba el dato de que, según el mismo Corral, en una petición que presentaba en octubre de 1607 a Miguel de Ibarra, alegaba haber construido siete puentes en el distrito de esa Real Audiencia ${ }^{50}$, pero hasta ahora no se conocía, aparte de los citados por Ibarra, de qué puentes se trataba ${ }^{51}$.

\footnotetext{
clavos de palmo y medio y de a palmo, y 44 picos que calzaba cada semana, más de 4 barrenas grandes, una azuela, una cerradura, unas espuelas pulidas, que suponemos se las encargaria Juan del Corral, y otras cosas, además del alquiler de su fragua y de la tienda que llevó, todo lo cual se lo entregó a dicho maestro. Por todo ello le debían 150 patacones. Francisco Namina, cacique del pueblo de Cavisa, declaraba que se le debían 3.000 ladrillos y el porte de la cal. Francisco Anaguano, cacique del pueblo de Tanta, reclamaba lo que se le adeudaba por el porte de las maderas y otras cosas.

45 Una semblanza de Corral y un estudio de su actividad profesional en Quito y Lima, donde se documentan once y nueve obras respectivamente, en WEBSTER, Susan V.: Quito, Ciudad de Maestros: Arquitectos, Edificios y Urbanismo en el largo siglo XVII, Edic. Abya-Yala, Quito, 2012, pp. 129-163. En mayo de 1603 Corral capitulaba con el Cabildo la reconstrucción del puente de Guayllabamba (p. 134).

46 AGI, Quito, 9, R. 9, N. 69.

47 AGI, Quito, 9, R. 10, N. 78.

48 Hacia 1644 el licenciado Fernando de Montesinos, en sus Anales del Perú, hacía una descripción del puente (WEBSTER, Susan V.: Quito, Ciudad de Maestros..., op. cit., pp. 134-135). 49 COSTALES, Piedad y Alfredo: Los agustinos, pedagogos y misioneros del pueblo, 1573-1869, Edit. Abya Yala, Quito, 2003, p. 12.

50 FERNÁNDEZ, Carmen: Arte colonial Quiteño. Renovado enfoque y nuevos actores, FONSAL, Quito, 2007, p. 199.

51 Webster señala que a petición del Cabildo emprendió en 1604 la construcción de un puente cerca del pueblo de Alangasí (WEBSTER, Susan V.: Quito, Ciudad de Maestros..., op. cit., p. 139).
} 


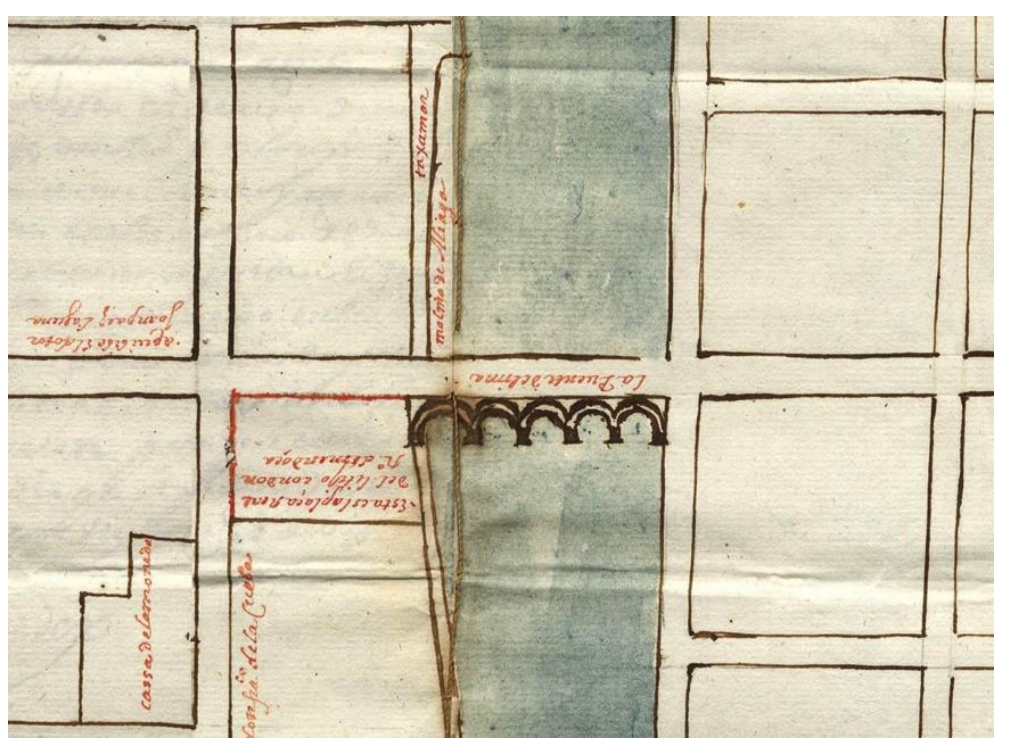

Imag. 13. El puente de Lima esquematizado en un plano de 1611 (AGI, Perú-Chile, 6)

Por la información de Corral en su petición sobre haber dado siete puentes en el distrito, y por la reiteración de los testigos de la residencia a Alvarado - señalando esa misma cifra de siete puentes construidos durante su mandato-, quedaba claro su número; y en cuanto a cuáles fueron, en al menos cuatro se reconocía su participación: Pisque, Tumbaco, Guayllabamba y Chillo. Los restantes puentes que numeraba Corral deben ser los ya señalados de Guápulo, Alangasí y alguno de los de las quebradas de Chiche y Pedro Díaz.

En las anteriores declaraciones que hemos comentado, realizadas en junio de 1604 para la residencia de don Lope de Mendoza, los testigos deponían que de los cinco puentes de piedra proyectados se habian terminado los de Guayllabamba, Tumbaco y Guápulo, habiéndose comenzado los de Alangasí y Pintag, que ya tenían acabados los primeros arcos. Después de finalizar estos dos últimos puentes hemos verificado que Corral siguió trabajando en Quito por lo menos hasta finales de 1607 , trasladándose poco después a Lima, donde en enero de 1610 -durante la construcción del nuevo puente de piedra sobre el río Rímac ${ }^{52}$ - , sería nombrado maestro mayor de la ciudad53. Para la financiación de este puente se echaron 20.000 pesos de derrama (un tomín por cada indio) en los corregimientos de Latacunga, Riobamba, Otavalo, y otros del distrito de la Audiencia de Quito. En enero de 1611 el oidor Diego de Zorrilla, recién llegado a Quito, avisaba al rey de que, aunque el Cabildo de Quito se habia quejado de esa derrama arguyendo que ellos habian levantado los puentes de su distrito sin que contribuyese Lima en cosa alguna, y su provincia estaba muy distante de aquella, donde jamás iban -y menos los indios-, por lo que no pensaban colaborar en ella, y además no podian porque les estaba

52 E1 20 de enero de 1610 la Audiencia se quejaba al rey de que se les había enviado el reparto para la obra de este puente, de lo cual ya se había quejado el Cabildo al virrey, sin embargo de lo cual ordenó la repartición. En este documento se cuantifica que tocaron a españoles y naturales de la Audiencia de Quito 15.000 pesos (AGI, Quito, 9, R. 13, N. 97). Esta fecha parece indicarnos que al menos el año anterior (1609) ya debian estar en marcha las labores del puente, y por lo tanto Corral se encontraba en Lima. En un plano de 1611, copia de otro anterior de 1610, en el que se representan algunas manzanas de la ciudad de Lima en el arrabal de San Lázaro, donde estaba construido el puente, junto al molino de Aliaga, aparece dibujado con cinco arcadas, de las seis que tiene (AGI, MP-Perú-Chile, 6, f. $^{\circ} 4 \mathrm{v} .{ }^{\circ}$. Reseñado en JOFFRÉ, Gabriel Ramón: "Ilustrar la urbe: planos de Lima Borbónica». Ilapa, n. ${ }^{\circ}$ 7, 2010, p. 65).

53 SAN CRISTÓBAL, Antonio: "Los Alarifes de la ciudad de Lima durante el siglo XVII", Laboratorio de Arte, 6 (1993), p. 132. 


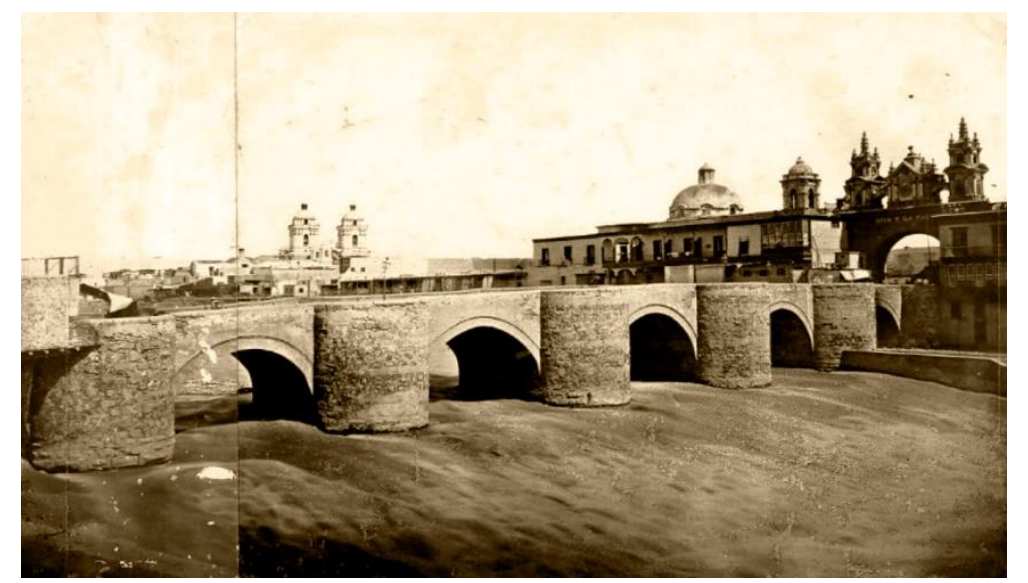

Imag. 14. El puente de Juan del Corral sobre el río Rimac, en Lima (idp)

prohibido ir de una provincia a otra. Alegaban otras razones, pero no les valió ninguna ni osaron negarse, porque el corregidor los habia amenazado con enviarlos a Lima. Su parecer se resumía en permitir la construcción del puente si resultaba conveniente, pero no era indispensable la suntuosidad ni un elevado coste, aparte de que la obra debían costearla los beneficiados por ella, que eran los de la provincia de Lima y no los de Quito.

Cuando el Cabildo pensó en sustituir a Corral como maestro mayor de las obras de la ciudad, ese mismo día decia: Tengo mirado a las personas maestros que hay en esta ciudad más prácticos y aspectos para poder ser alarifes, de los cuales son Francisco Bázquez, Diego Guillén, Antonio Mayordomo, Pedro Blasco, personas que me parece con puntualidad acudirá. E1 maestro Diego Guillén aparecerá como alarife de la ciudad en el periodo 1610$1621^{54}$, y entre las obras que llevó a cabo en ese tiempo se encontraba el puente de Apurimac, cuyo

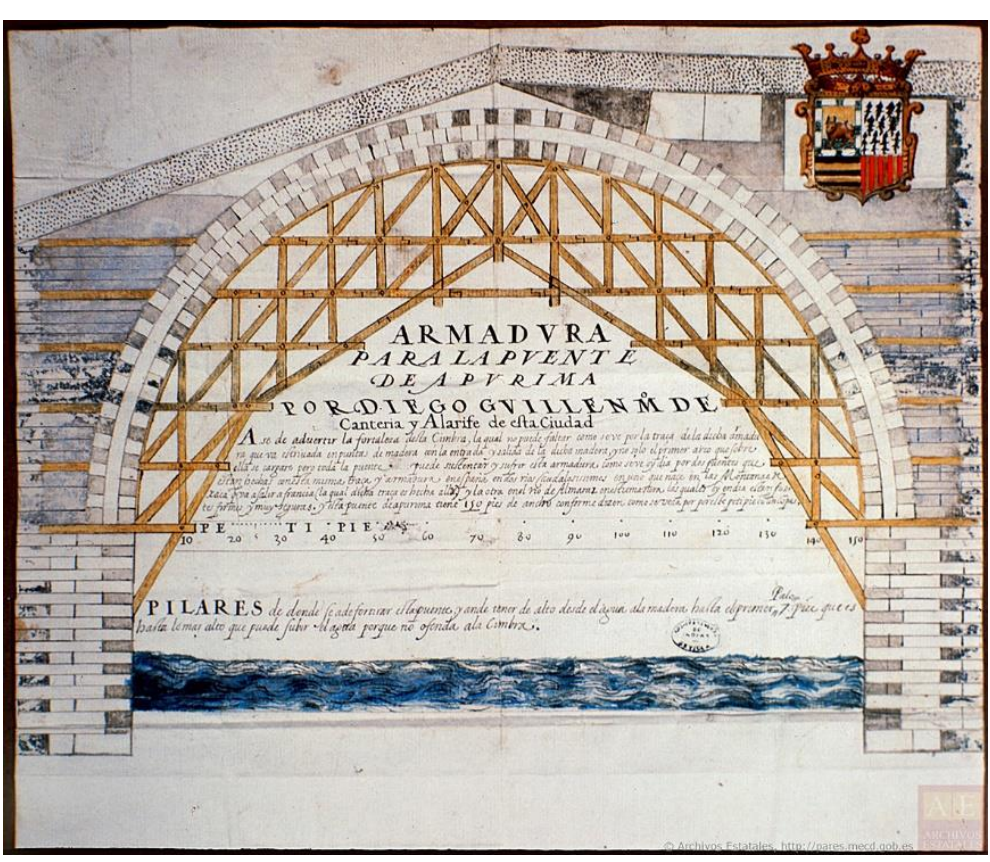

Imag. 15. Cimbra del puente de Apurimac sobre el río Pachachaca. Año 1619. Escudo de armas del virrey Francisco de Borja y Aragón (AGI. MP. Perú-Chile, 203) plano aparece hoy en multitud de publicaciones ${ }^{55}$. Fue mandado edificar por el entonces virrey don Francisco de Borja en 1619 siguiendo el modelo de puente de un solo ojo sobre

54 Ibid., p. 150.

55 Texto en imagen 15. Leyenda: Armadura para la puente de Apurima por Diego Guillén, maestro de canterias y alarife de esta ciudad. Ase de advertir la fortaleza desta cimbra, la qual no puede faltar, como se ve por la traça de la dicha armadura, que va estrivada en puntas de madera con la entrada y salida de la dicha madera y no solo el primer arco que sobre ella se cargare; pero toda la puente puede sustentar y sufrir esta armadura, como se ve oy dia, por 
bóveda de medio punto apoyada sobre fuertes pilastras, construidas sobre unas cimbras de madera a base de tirantes y camones inclinados, anclados aquellos largamente en las pilastras laterales. Aunque el modelo se venía usando ya desde finales del siglo XVI, no por ello dejaba de ser en este caso una gran obra de ingeniería pensada para cubrir una luz de aproximadamente $42 \mathrm{~m}$, que son los 152 pies señalados en el plano ${ }^{56}$.

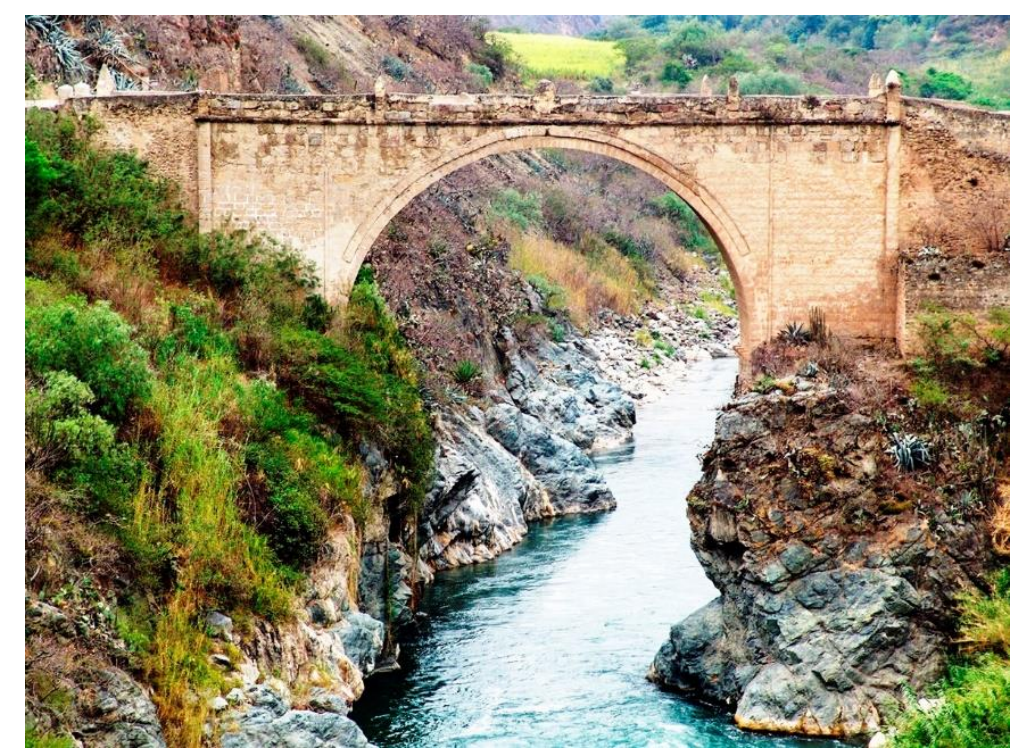

Imag. 16. Puente colonial sobre el río Pachachaca.

(idp)

dos puentes que están hechas con esta misma traça y armadura en España en dos rios caudalosíssimos: en uno que nace en la Montañas de Xaca, que va a salir a Francia (la qual dicha traça es echa allá), y la otra en el rio de Almaraz, en Estremadura, las quales oy en día están fuertes y muy seguras. Y esta puente de Apurima tiene 150 pies de ancho, conforme dicen, como se verá por este petipie con un compás. Pilares. De donde se a de fortificar esta puente y an de tener de alto desde el agua a la madera hasta el primer palo 7 pies, que es hasta lo más alto que puede subir el agua, porque no ofenda a la cimbra.

56 Encontramos alguna información en la que se señala que el diseño de Guillén hizo posible que el puente se mantuviese en pie hasta hoy en día, y muestra junto al citado plano el actual puente colonial existente en Abancay, en el departamento de Apurimac, sobre el río Pachachaca. Este segundo puente, con una luz de 20,50 m, según la ficha de la Dirección de Cultura de Apurimac, se inició en 1654 por orden del virrey conde de Salvatierra. Para otros el puente es de 1564, mandado construir por el virrey marques de Cañete, citando una declaración de testigos de 1586 sobre el pueblo de Abancay y otros, en la que se afirma que en un río muy caudaloso llamado Hamancay había una puente grande de piedra (FORNER, Nicolás de: "Breve relación de la tierra del corregimiento de Abancay, de que es corregidor Niculoso de Fornee", en JIMÉNEZ DE LA ESPADA, Marcos: Relaciones Geográficas de Indias, tomo I, Biblioteca de Autores Españoles, Madrid, 1965). Se vuelve a citar un puente de cal y canto en el valle de Amancay hacia 1591 (LIZARRAGA, Reinaldo fray: Descripción breve de toda la tierra del Perú, Tucumán, Rio de la Plata y Chile, Instituto Histórico del Perú, Lima, 1908). 